Article

\title{
Assessment of Ocean Swell Height Observations from Sentinel-1A/B Wave Mode against Buoy In Situ and Modeling Hindcasts
}

\author{
He Wang 1,2,*(D), Alexis Mouche ${ }^{2} \mathbb{D}$, Romain Husson ${ }^{3}$, Antoine Grouazel ${ }^{2} \mathbb{D}$, Bertrand Chapron ${ }^{2}$ \\ and Jingsong Yang ${ }^{4}(\mathbb{D}$ \\ 1 National Ocean Technology Center, Ministry of Natural Resources, Tianjin 300112, China \\ 2 Laboratoire d'Océanographie Physique Spatiale, Centre de Brest, Ifremer, 29280 Plouzané, France; \\ alexis.mouche@ifremer.fr (A.M.); antoine.grouazel@ifremer.fr (A.G.); bertrand.chapron@ifremer.fr (B.C.) \\ 3 Collecte Localisation Satellites, 29280 Plouzané, France; rhusson@groupcls.com \\ 4 State Key Laboratory of Satellite Ocean Environment Dynamics, Second Institute of Oceanography, \\ Ministry of Natural Resources, Hangzhou 310012, China; jsyang@sio.org.cn \\ * Correspondence: wanghe_sio@126.com; Tel.: +86-22-2753-0334
}

check for

updates

Citation: Wang, H.; Mouche, A.; Husson, R.; Grouazel, A.; Chapron, B.; Yang, J. Assessment of Ocean Swell Height Observations from Sentinel-1A/B Wave Mode against Buoy In Situ and Modeling

Hindcasts. Remote Sens. 2022, 14, 862. https://doi.org/10.3390/rs14040862

Academic Editors: Weizeng Shao, Andrea Buono and Carina Regina de Macedo

Received: 30 December 2021

Accepted: 7 February 2022

Published: 11 February 2022

Publisher's Note: MDPI stays neutral with regard to jurisdictional claims in published maps and institutional affiliations.

Copyright: (c) 2022 by the authors. Licensee MDPI, Basel, Switzerland. This article is an open access article distributed under the terms and conditions of the Creative Commons Attribution (CC BY) license (https:/ / creativecommons.org/licenses/by/ $4.0 /)$.

\begin{abstract}
Synthetic Aperture Radar (SAR) in wave mode is a powerful tool for monitoring sea states in terms of long-period ocean swells of a specific wave directional partition. Since 2016, SARs aboard Sentinel-1A/B operating in wave mode have provided ocean swell spectra dataset as Level-2 Ocean products on a continuous and global basis over open oceans. Furthermore, Level-3 swell products are processed by Copernicus Marine Environment Monitoring Services (CMEMS) taking the benefit of the unique "fireworks" analysis. In this paper, swell wave heights from Sentinel-1A/B wave mode during the period from June 2016 to June 2020 are evaluated. The reference data include the collocated in situ measurements from directional wave buoys and WaveWatch III (WW3) hindcasts. Assessment results show systematic overestimation of approximately $0.2 \mathrm{~m}$ in terms of the partitioned swell heights for Sentinel-1A/B Level-2 products compared to the directional buoy observations in eastern Pacific and the western Atlantic. Based on the reliable SAR-WW3 collocations after quality-controls, empirical corrections have been proposed for Sentinel-1 Level-2 swell heights. Independent comparisons against WW3 hindcasts and buoy observations demonstrate the validity of our postprocessing correction for both Level-2 and Level-3 swell heights by eliminating the biases and reducing the root mean square errors. The consistency between CMEMS Level-3 swells and buoy in situ is also examined and discussed by case studies.
\end{abstract}

Keywords: swell; synthetic aperture radar; wave mode; validation; buoy; WaveWatch III; wave partition

\section{Introduction}

Swells are long-period ocean waves, which are generated by remote storms and are weakly affected by the local wind. It is estimated that most of the waves across the World Ocean are these long-period ocean swell waves [1]. These strongly swell-dominated areas, known as a swell pool [2,3], act as a response and/or impact factor for climate change [4,5]. Since the 1990s, the spaceborne Synthetic Aperture Radar (SAR), especially thanks to the so-called WaVe mode (WV), adopted by European Space Agency (ESA) C-band SARs on ERS-1/2 [6], Envisat [7], and the Chinese SAR satellite Gaofen-3 [8,9] and now the European Sentinel-1 constellation, allows for directional ocean swell spectra measurements in the longer wavelength regime, providing a unique describing of the complex sea states at a global scale.

Sentinel-1 is the ESA Copernicus constellation of SAR satellites globally providing WV acquisitions in the open ocean. Sentinel-1A, carrying the C-band (a center frequency of 5.405 GHz) SAR, was first launched into orbit on 3 April 2014, and was then followed by the 
identical satellite Sentinel-1B launched on 25 April 2016. As part of the ESA's Copernicus catalog, Sentinel-1 data acquired over the ocean are systematically processed into Level-2 OCeaN (OCN) products. In particular, these Level-2 OCN WV products contain directional ocean wave spectra retrievals in the so-called Ocean Swell Wave (OSW) component. It is worth noting that the north Atlantic basin is not well covered by WV acquisitions. Indeed, Sentinel-1 has four different exclusive modes and acquire specific data in wide swath modes over European waters for other Copernicus applications. In addition, SAR-retrieved swells spectra from WV still suffer from limitations for a seamless use by the ocean wave community (e.g., [10,11]). First, bad or suspicious results exist owing to the complexity of the retrieval (e.g., the nonlinear SAR-ocean wave imaging mechanism or contamination of SAR images by non-wave phenomena). Then, the along-track Level-2 SAR ocean wave observations are still inadequate to depict the globally propagating swell across the oceans with a homogeneous and regular sampling in both time and space.

Recently, the ocean swell propagation technique, pioneered by Snodgrass et al. [12] and Munk et al. [13], used to locate the storm sources responsible for swell observations at buoy stations, has been revisited with remote sensing data. This technique has been employed to propagate the observed Envisat ASAR swells across the ocean basin, which is referred to as "fireworks" from their visual view when represented on a world map or regional view [14-16], and then used to study the swell dissipation across oceans [17,18], to characterize the time and space structures of swells [19]. The "fireworks" technique also opened up perspectives for producing a higher level of SAR-derived swells. This has led to a new Level-3 wave product proposed in the framework of Copernicus Marine Environment Monitoring Services (CMEMS) [20].

SAR ocean wave acquisitions have proven to benefit the numerical wave model community to propose new modeling developments $[17,21]$ or for assimilation in operational systems, e.g., [22]. In this context, the detailed statistical knowledge of quality assessments on the Sentinel-1A/B (S-1A/B) SAR swell height products (both Level-2 OCN and CMEMS Level-3 "fireworks") are of vital importance for these research and applications. Some efforts have been devoted for the evaluation of the Sentinel-1A/B Level-2 OCN wave products (e.g., [23-26]) or CMEMS Level-3 [27], but few focus on jointly evaluating and analyzing Level-2 and Level-3 swells. The present work aims to validate Sentinel-1A/B wave mode swell wave height provided in ESA Level-2 OCN and CMEMS Level-3 products against wave numerical hindcasts and buoy observations.

The remainder of the paper is organized as follows. Following the Introduction, in Section 2, Sentinel-1A/B level-2 products and the CMEMS Level-3 swell products are described. The reference data and results of the assessment of Sentinel-1A/B Level-2 SARderived swell heights are given in Sections 3 and 4, respectively. In Section 5, we present the correction model of Sentinel-1A/B Level-2 swell heights. In Section 6, we discuss the performance of CMEMS Level-3 swell height products, followed by two typical cases in Section 7 . The findings of this study are summarized in Section 8.

\section{Sentinel-1 Wave Mode Swell Products}

This study utilized Sentinel-1A/B wave mode data covering four years between June 2016 and June 2020. The processing of Sentinel-1A/B wave mode data from Level-1 to Level-2 and Level-3 are briefly shown in Figure 1 and will be detailed below.

\subsection{Sentinel-1 Wave Mode Level-2 Data}

Sentinel-1A/B WV operates in the so-called "leap frog" acquisition mode, in which a SAR image (or imagette) is acquired every $100 \mathrm{~km}$ at two alternating incidence angles (approximately $23.5^{\circ}$ and $36.5^{\circ}$, called WV1 and WV2, respectively). Images acquired at the same incidence are $200 \mathrm{~km}$ apart. Each SAR WV image is about $20 \times 20 \mathrm{~km}$ with a $5 \mathrm{~m}$ spatial resolution and is acquired in VV polarization (default). Figure 2 (left) illustrates a typical example of a Sentinel-1 WV imagette, presenting a clear wavy pattern acquired at 23.18 $\mathrm{S} / 91.03^{\circ} \mathrm{W}$, on 11:39:54 Universal Time Coordinated (UTC), 11 September 2016. 


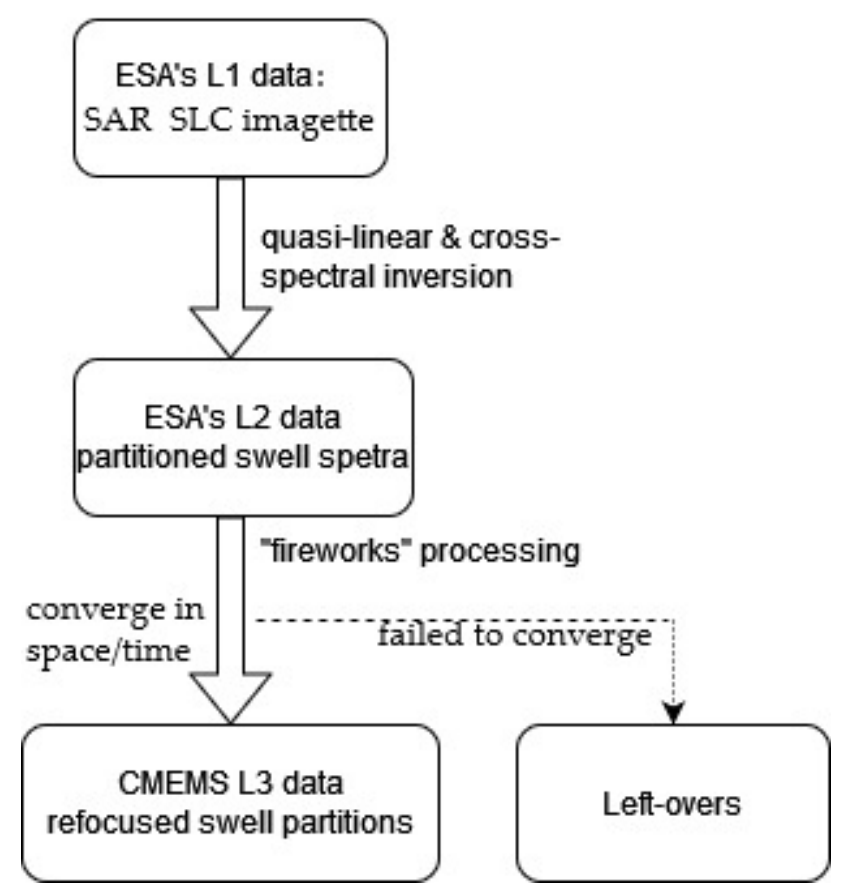

Figure 1. Flow chart of the processing of Sentinel-1A/B wave mode products from L1 to L3.

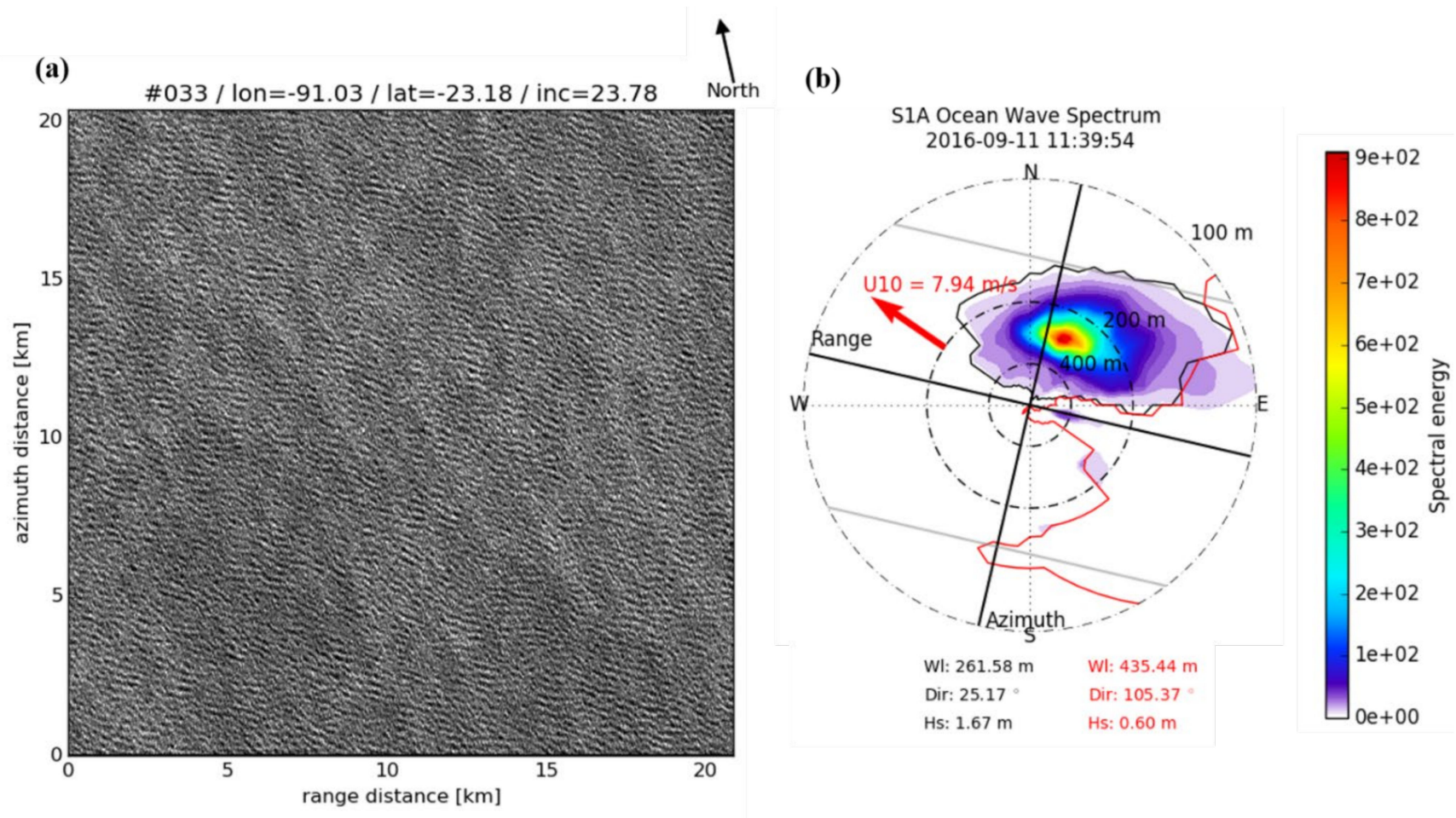

Figure 2. (a) Sentinel-1A wave mode roughness image acquired on 11:39:54 UTC 11 September 2016 at $23.18^{\circ} \mathrm{S} / 91.03^{\circ} \mathrm{W}$, and (b) corresponding Level-2 ocean swell spectrum.

The OSW component of the Level-2 OCN product is estimated from the Level-1 single look complex (SLC) SAR imagette using ESA Level-2 spectral inversion unit. Based on the quasi-linear approximation SAR-Ocean imaging mechanism, after estimating and removing the non-linear contribution, the OSW inversion scheme employs the cross spectra technique to remove the $180^{\circ}$ directional ambiguity in the wave propagation direction, and to avoid the use of a priori wave information from numerical wave model $[28,29]$. These swell spectra retrievals are with $10^{\circ}$ resolution in directions and 30 exponentially 
spaced wavenumbers ranging from 30 to $800 \mathrm{~m}$. An example of ESA's Level-2 ocean wave spectrum derived from the imagette represented in Figure 2 (right) could be found.

After the inversion, the two-dimentional ocean wave spectrum is partitioned into different ocean wave systems up to five, followed by the computation of integral parameters of swell significant wave height, the peak wave period, and peak direction for each partition [30]. As shown in the Level-2 spectrum in Figure 2, two wave partitions are delineated in different colored lines, and their characteristics in terms of significant swell height, the peak wave period, and peak direction are presented in the corresponding colors.

Note that SAR-observed swells are here selected using the criterion of wavelength $>200 \mathrm{~m}$ and significant swell height $>0.3 \mathrm{~m}$ to reject wind-sea partition and wave systems with too low energy, respectively.

\subsection{Copernicus/CMEMS Level-3 "Fireworks" Swell Products}

Sentinel-1 Level-2 swell partitions are further analyzed to produce the higher-level Level-3 data, gathering all the swell measurements originating from the same storm event, using the so-called SAR "fireworks" analysis. To us, the two motivations for exploiting this new product are: (i) to reject the anomalies contained in the Level-2 data; and (ii) to obtain consistent swell fields and their evolution in space and time for each storm and possibly analyze them. The main steps of "fireworks" processing are as follows [14,16,31].

(1) Retro-propagation

The Level-2 swells are retro-propagated along the great circles, neglecting wavecurrent interactions in deep water, over the ocean every $3 \mathrm{~h}$. Given the SAR measured swell peak period $T$ and propagating direction $\theta$, neglecting wave-current interactions in deep water, the retro-propagated swells are calculated along the great circle starting off with the observed location in direction $\theta+\pi$ at the theoretical group velocity:

$$
C_{g}=g T /(4 \pi),
$$

where $g$ represents the acceleration of gravity.

(2) Refocusing and swell origin identification

The swell origins are identified by seeking the spatiotemporal convergence of the retro-propagated trajectories.

As illustrated in Figure 3 (left), a storm event on 28 July 2016 12:00 UTC, generated from the southeast Pacific (centered at $38.22^{\circ} \mathrm{S}, 144.09^{\circ} \mathrm{W}$ ) depicted as a red disk, is defined as spatio-temporal convergence of the swell trajectories (gray lines) retro-propagated from the Sentinel-1A/B WV acquisitions (color points). Accordingly, from a map of blended winds from Institut Français de Recherche pour l'Exploitation de la Mer (Ifremer) [32] (see right panel of Figure 3), high wind speeds up to 50 knots could be found at that time for an extra-tropical storm event (white plus for the center, and white dashed line for the region identified from the Sentinel-1 refocused analysis).

In another example presented in Figure 4 (left), the retro-propagated swell observations converge in the Northwest Pacific near Japan (centered at $29.003^{\circ} \mathrm{N}, 147.307^{\circ} \mathrm{E}$ ) on 29 August 2016. This refocusing area corresponds to the Typhoon Lionrock. In addition to the blended winds map (right of Figure 4), Lionrock was also captured twice by Sentinel-1 SAR in extended wide swath mode on 27th 20:49 UTC and 29th 20:34 UTC in this region (see their Figure 4 and Figure 6 in [33]).

These two cases will be further discussed in Section 7.

(3) Consistent swells association: Level-3 products

Finally, the "fireworks" analysis splits the S-1A/B Level-2 swells into two categories: refocused data (converging swell partitions) and left-overs (those that failed to converge). Furthermore, given the origin of swells, the swell evolutions (peak wavelength, direction, and swell height for each propagation time/position up to 10 days) are predicted apart from the origin until the coast, according to the linear wave propagation theory and swell dissipation law $[14,17]$. 


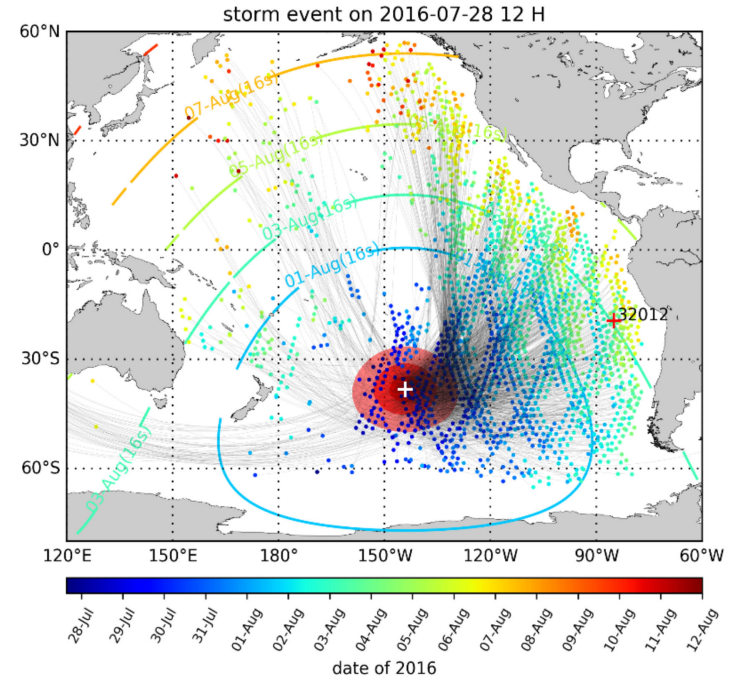

(a)

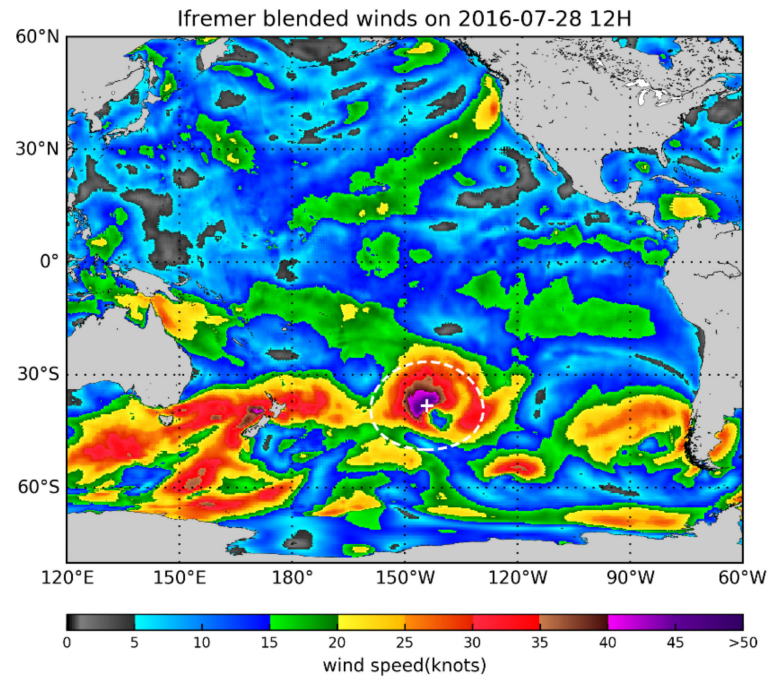

(b)

Figure 3. (a) Illustration of "fireworks" analysis for the case of extra-tropical storm (28 July 2016 12:00 UTC, centered at $38.22^{\circ} \mathrm{S} / 144.09^{\circ} \mathrm{W}$ ) generated swell event. Trajectories (gray lines) of Sentinel-1 swell observations (colors indicating the acquired time) associated to the storm (white plus and red disk represent storm center and coverage). The colored solid lines represent the swell predicting location at different arrival times from the swell source. (b) Ifremer blended winds on 28 July 2016 12:00 UTC. The center and size of swell generation area for this event inferred from the "fireworks" are represented by a white plus and dash line.

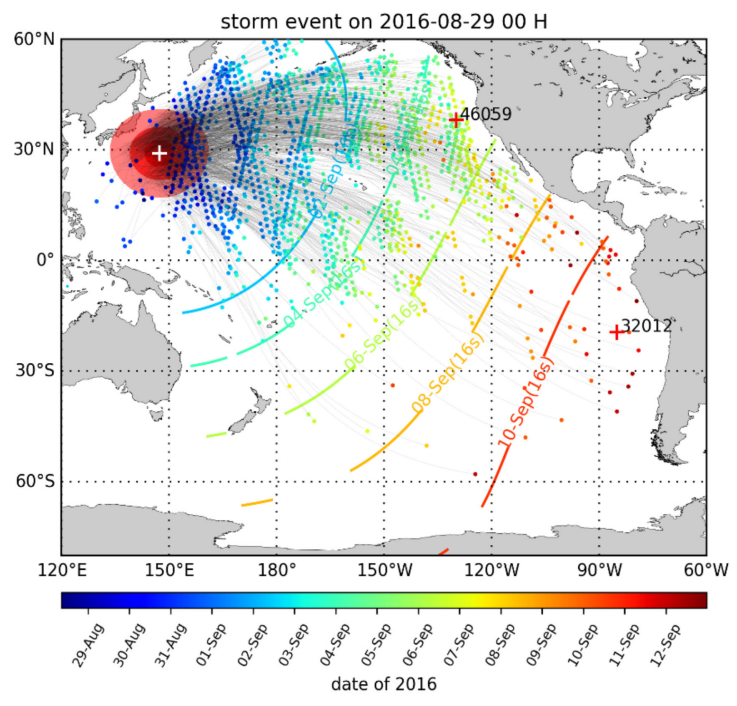

(a)

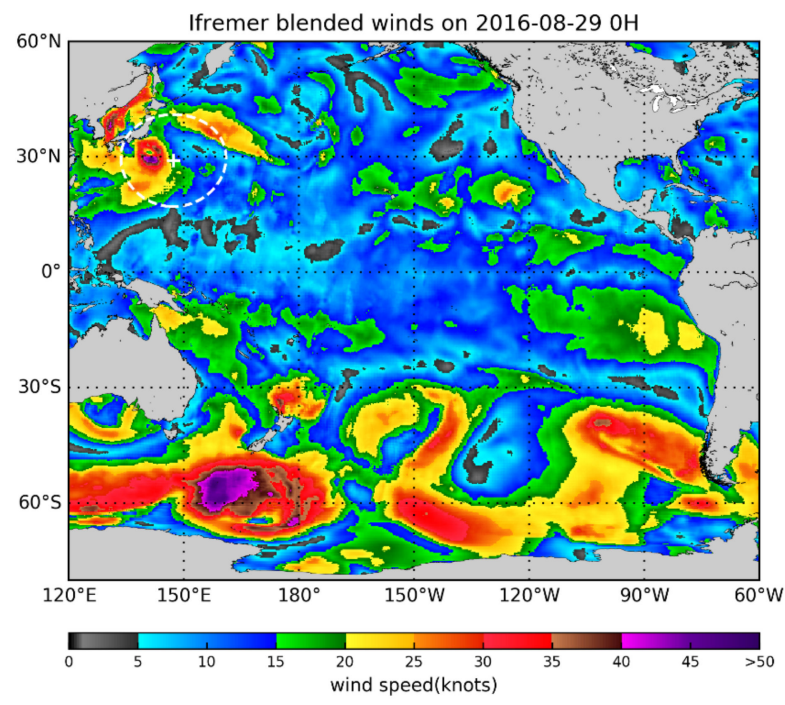

(b)

Figure 4. As in Figure 3, but for the case of a swell event originated from Typhoon Lionrock on 29 August 2016 00:00 UTC, centered at $29.0^{\circ} \mathrm{S} / 147.31^{\circ}$ E. (a) Illustration of "fireworks" analysis. (b) Ifremer blended winds.

Figure $5 \mathrm{a}, \mathrm{b}$ shows the locations S-1A/B Level-2 swells generated by the extra-tropical storm (28 July 2016, see Figure 3) and other storms, respectively. Note that this S-1A/B distribution map in the Pacific (Figure $5 b$ ) is in line with a previous study regarding ocean swell distribution [3]. In contrast, the locations of leftovers, i.e., S-1A/B Level-2 swells that failed to converge over the period from 29 July to 11 August 2016 are shown in Figure 5c. 


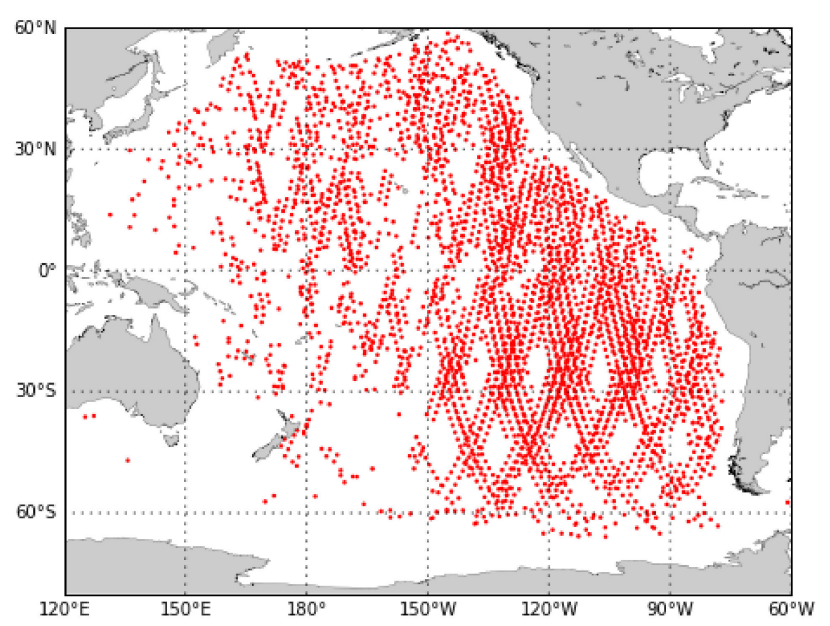

(a)

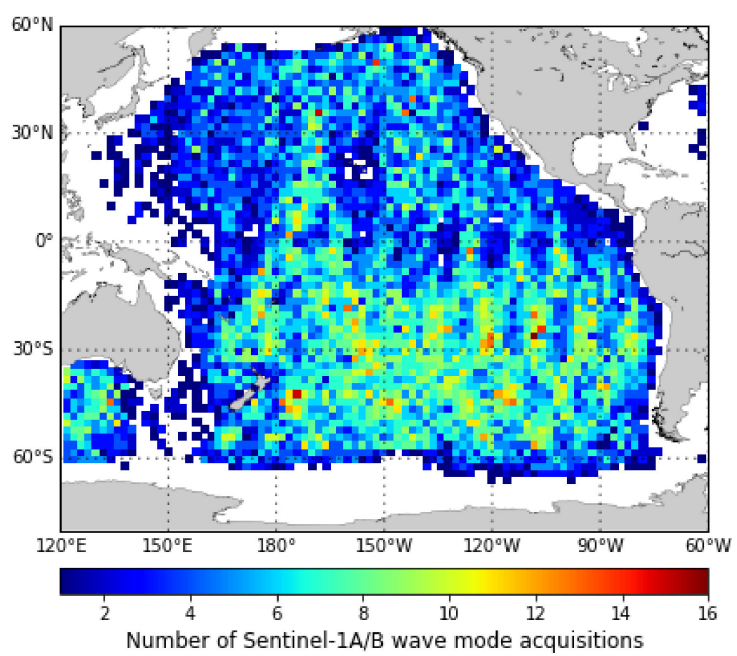

(b)

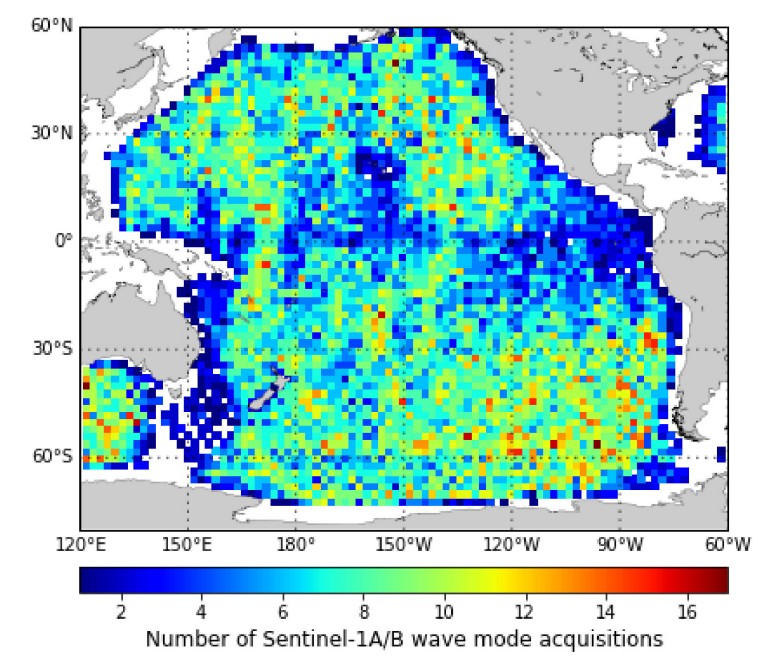

(c)

Figure 5. Distribution of Sentinel-1A/B wave mode acquisitions over the period from 29 July 29 to 11 August 2016. (a) Data associated to the swell event illustrated in Figure 3. (b) Data associated to other swell events. (c) Data failed to converge to any sources.

\section{Reference Data}

\subsection{Buoy Measurements}

A total of 24 deep-water buoys providing the directional ocean wave data are selected as ground truth in this study. As shown in Figure 6, the buoys are deployed off the east and west coasts of the America continent (especially concentrated off the California coast, see the zoomed map), and around the Hawaii islands. The directional ocean wave buoys used here are from two mooring networks of the National Data Buoy Centre (NDBC) [34] and the Coastal Data Information Program (CDIP) [35], containing buoys of $3 \mathrm{~m}$ heave-pitch-roll and Datawell Directional Waverider, respectively.

A 3-h running averaging is applied to minimize the fluctuation in the hourly "first five" wave moments measured by the buoy. These five moments include the non-directional energy frequency spectrum $E(f)$, and other four directional distribution moments. In order 
to reconstruct the full two directional spectrum $S(f, \theta)=E(f) \times D(f, \theta)$, the directional distributions $D(f, \theta)$ is estimated using the maximum entropy method [36]:

$$
D(f, \theta)=\frac{1}{2 \pi}\left(1-\varphi_{1} c_{1}^{*}-\varphi_{2} c_{2}^{*}\right) /\left|1-\varphi_{1} e^{-i \theta}-\varphi_{2} e^{-2 i \theta}\right|^{2},
$$

where * denotes complex, $c_{1,2}=a_{1,2}+i b_{1,2}$ and $\varphi_{1}=\left(c_{1}-c_{2} c_{1}^{*}\right) /\left(1-\left|c_{1}\right|^{2}\right)$, $\varphi_{2}=c_{2}-c_{1} \varphi_{1}$. Here, $a_{1}, b_{1}, a_{2}, b_{2}$, which are all functions of frequency $f$, are the four Fourier coefficients reported by CDIP buoys. For the NDBC buoys, directional Fourier moments of $r_{1}, \alpha_{1}, r_{2}, \alpha_{2}$ are provided instead, which could be converted as follows:

$$
\begin{gathered}
a_{1}=r_{1} \cos \alpha_{1} ; b_{1}=r_{1} \sin \alpha_{1} \\
a_{2}=r_{2} \cos 2 \alpha_{2} ; b_{2}=r_{2} \sin 2 \alpha_{2} .
\end{gathered}
$$

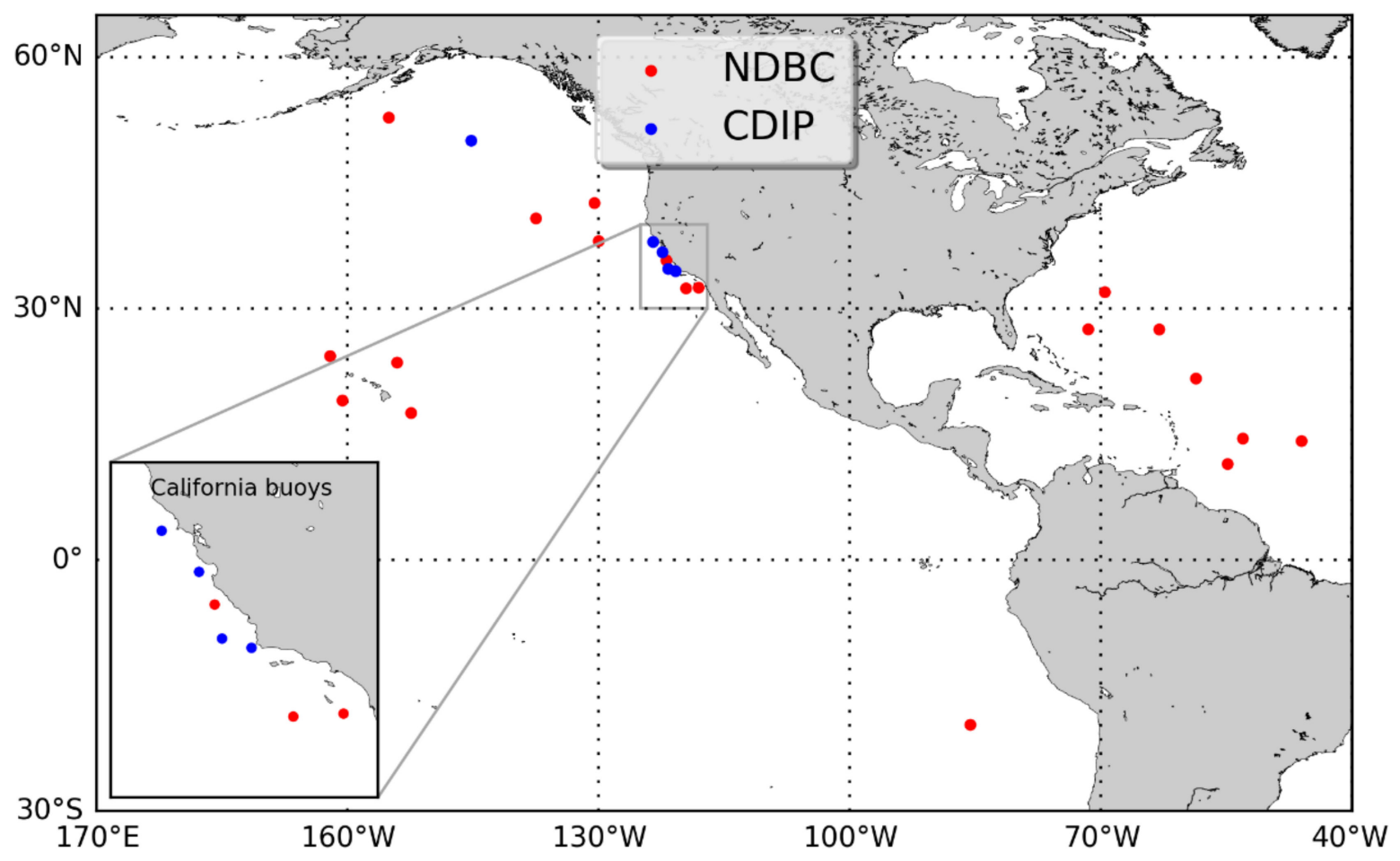

Figure 6. Location of directional wave buoys from the NDBC and CDIP networks.

Figure 7 presents a typical reconstructed 2D spectrum recorded by the Stratus buoy station (\#32012) located in the open ocean off the coast of Chile on 12:00:00 11 September 2016. The watershed partitioning algorithm [37] is then applied to the buoy spectra in order to separate the swell systems (defined by a peak wavelength larger than $200 \mathrm{~m}$ here). In addition, the partition peak-to-boundary energy ratio $R p b$, defined as peak energy divided by the maximum energy along the boundary for the corresponding wave partition, is used to do the quality check of the buoy swell partition [31]. Only buoy swells with $R p b>1.0$, indicating a predominant swell system through a well isolation partition scheme, remain and are used for validation.

In this study, we collocated the Sentinel-1 wave mode Level-2 acquisitions with the reference data from buoy by limiting the distance within $100 \mathrm{~km}$ and time separation to less than $30 \mathrm{~min}$. These limits were chosen because the Sentinel-1 wave mode acquisitions were $200 \mathrm{~km}$ apart in space along orbit at the same incidence, and the buoy records used here are hourly. 


\section{Buoy Ocean Wave Spectrum (32012)}

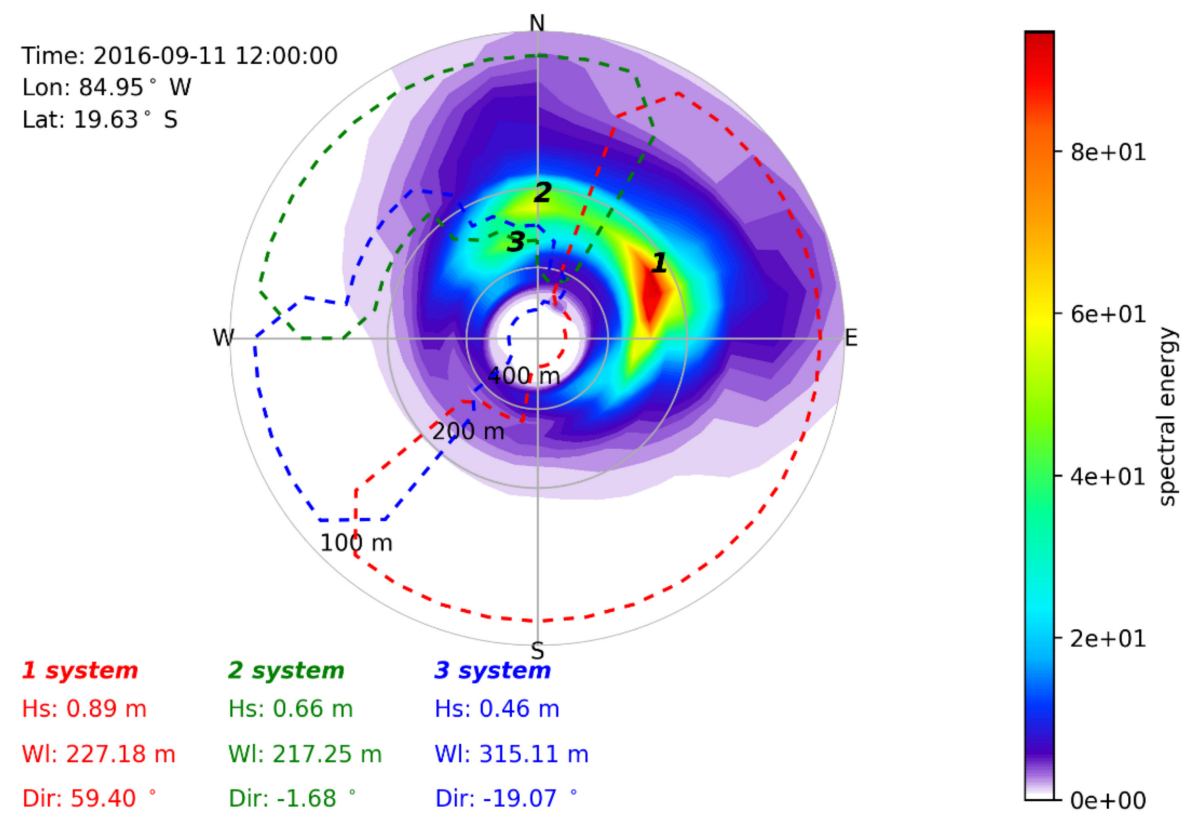

Figure 7. Buoy ocean wave spectrum from NDBC station $32012\left(19.63^{\circ} \mathrm{S} / 84.95^{\circ} \mathrm{W}\right)$ on 12:00:00 UTC 11 September 2016.

\subsection{WaveWatch III (WW3) Hindcasts}

In this study, we also used WW3 hindcasts complementing the buoy in situ. This numerical wave model, from the database of Integrated Ocean Waves for Geophysical and other Applications (IOWAGA) project of Ifremer, was performed with the updated parameterization forced by the European Centre for Medium-range Weather Forecasts (ECMWF) winds [38,39]. The spatial and temporal sampling of the WW3 hindcast is $0.5^{\circ}$ and $3 \mathrm{~h}$, respectively. As illustrated in Figure 8, the 2D WW3 spectrum has 24 directions and 31 exponentially distributed frequencies from $0.037 \mathrm{~Hz}$ to $0.7 \mathrm{~Hz}$. The hindcast output also contains up to six wave partitions, including one wind-sea (if it exists) and five swells.

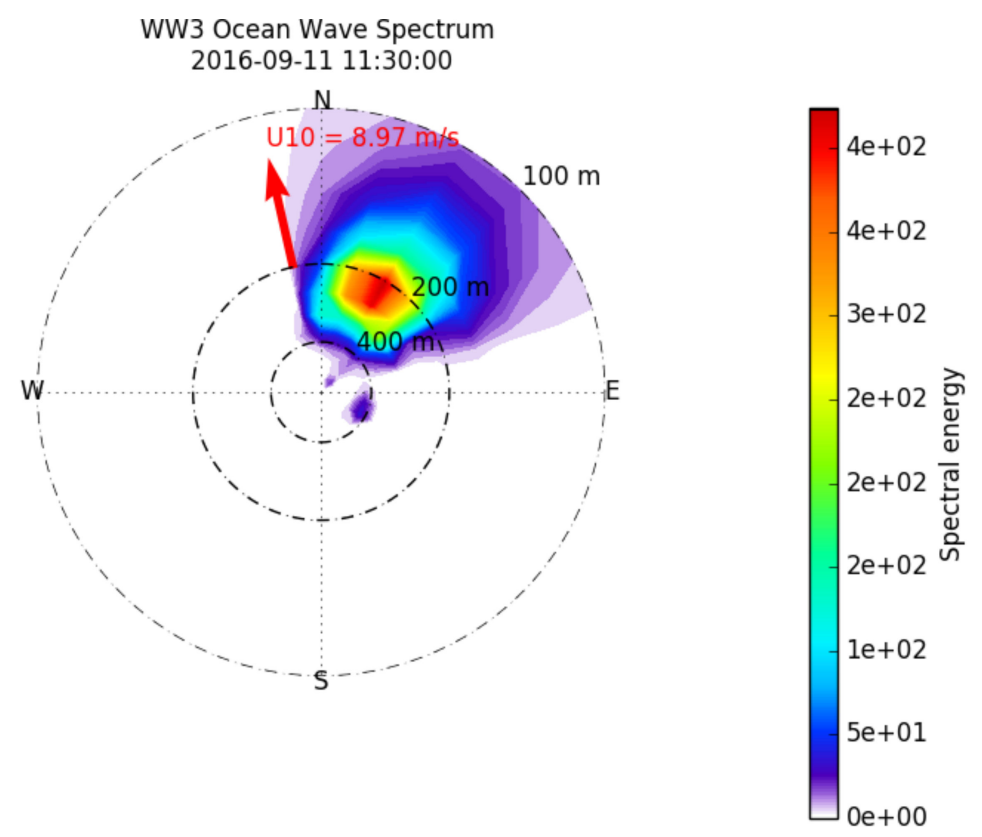

Figure 8. WW3 hindcast ocean wave spectrum on 11 September 2016 at $11: 30$ (UTC) at $23.0^{\circ} \mathrm{S} / 91.0^{\circ} \mathrm{W}$. 
A comparison of the partitioned swell heights from the Ifremer WW3 hindcast against those of the buoy observations was carried out. As shown in Figure 9, the accuracy of WW3 hindcast partitioned swell heights is $0.31 \mathrm{~m}$ in terms of RMSE along with negligible bias against in situ measurements from directional buoys. It should be emphasized here that this intercomparison was performed only in the specific region (see the map of Figure 6) where directional buoy data are publicly available, and for other areas, for instance in the Mediterranean, the WW3 model has a tendency to underestimate the total significant wave height under severe conditions [40].

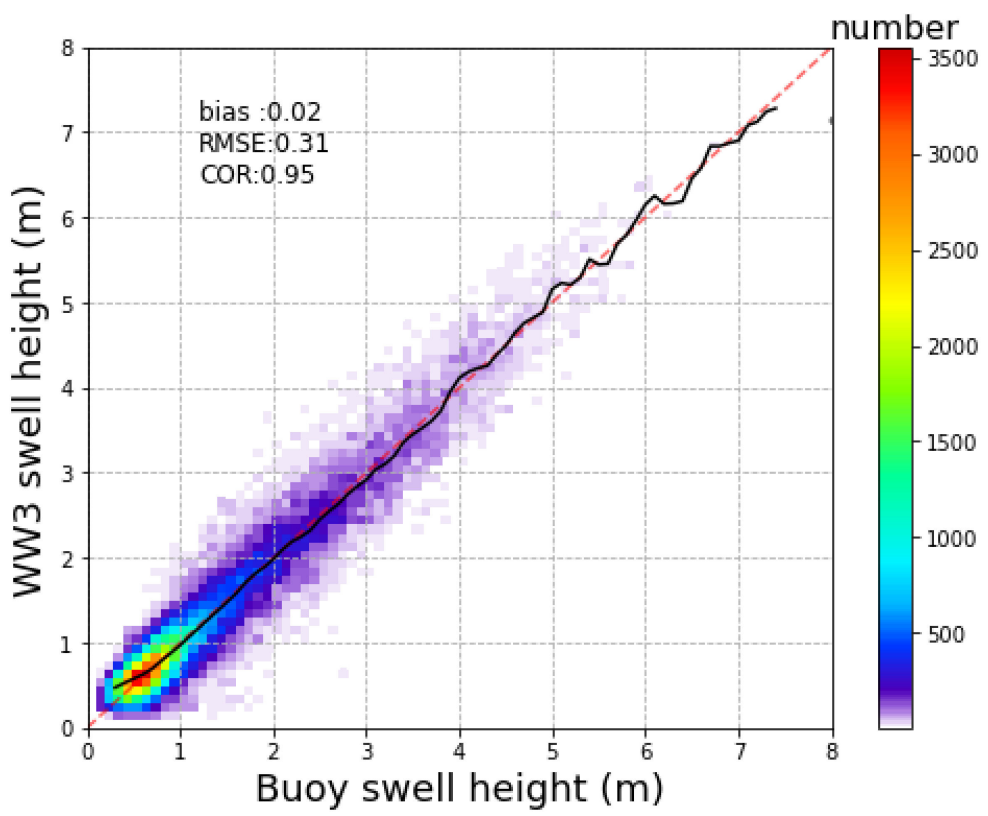

Figure 9. Intercomparisons of the partitioned swell heights for WW3 hindcast versus buoys.

\section{Quality Assessment of Sentinel-1 Level-2 Data}

\subsection{Match-Up Datasets}

In order to maximize the collocated samples for validating, Sentinel-1 wave mode acquisitions were collocated with the WW3 hindcasts from the closest space-time grid, i.e., within the window of $0.25^{\circ}$ and $1.5 \mathrm{~h}$.

In addition, the matchups of SAR-buoy/WW3 at the partitioned swell level were made from their spatio-temporal collocations. This means that the corresponding swell partitions from the SAR spectra records should be further associated with partitioned swell from the reference. In this study, WW3/buoy partitions are cross-assigned to SAR wave partitions by finding the nearest in the spectral domain. Here, we adopt the definition of spectral distance $D_{\text {spec }}$ between partitions from SAR and reference [31]:

$$
D_{\text {spec }}=1 / q\left(\left|D_{1}-D_{2}\right| \bmod 360+r\left|T_{1}-T_{2}\right| /\left(T_{1}+T_{2}\right)\right) \text {, }
$$

where $D_{i}$ and $T_{i}$ refer to the peak propagation direction and peak period of each swell system, respectively. The value of $r=250$ was chosen so that $20^{\circ}$ directional errors are equivalent to $8 \%$ errors in wave period, which are approximately the expected accuracies of SAR swell measurements. Then, $q=30$ was selected to ensure a $30^{\circ}$ error in direction and $12 \%$ in period to give a spectral distance equal to one.

Furthermore, the co-located swell partitions are filtered by the following quality controls.

(1) L2QC.

There is a quality flag for each swell partition in S-1A/B Level-2 products. This QC flag, annotated to be "good"," medium"," low", or "poor", is based on the criteria in terms of the wind speed, imagette normalized variance, partition contrast, and intensity of spectra normalized variance, offering the confidence of accuracy for the corresponding 
SAR retrieval (see [41] for details). Hence, by applying L2QC, only the most reliable data flagged as "good" remain. It is worth noting that L2QC was only introduced in June 2019 (Sentinel-1 processor version of 3.31). Thus, it is only possible to apply L2QC for the data after June 2019.

(2) L3QC.

According to our previous validation [27], the sub-dataset of Sentinel-1 SAR-derived swells that are refocused through "fireworks" processing has proven to be of better quality than the leftovers due to space-time consistency. That means the L3 Sentinel-1 wave mode processing could be regarded as another quality-control (L3QC) procedure that can filter out spatiotemporally inconsistent SAR retrievals. Thus, only the consistent refocused data in "fireworks" have remained using the L3QC in this study.

(3) WW3QC.

Additionally, to further exclude the suspicious Sentinel-1 Level-2 OCN spectra (resulting from bad partition, e.g., a large cutoff effect), we introduced a third quality-control using the corresponding 2D spectrum from WW3, which is called WW3QC hereinafter. The procedure is as follows: First, the partition boundary of SAR Level-2 was converted into the WW3 domain, and the swell height $H_{s s 1}$ was computed by integrating spectral values from WW3 over this SAR-derived partition. Then, we compared $H_{s s 1}$ against $H_{s s 2}$, which were directly obtained from co-located WW3 gridded partition. Note that both $H_{s s 1}$ and $H_{s s 2}$ are computed using WW3 modeled spectral values, while the former (latter) is integrated inside the partition boundary from SAR (WW3). Finally, only the data pairs with a small difference (i.e., $\left|H_{s s 1}-H_{s s 2}\right|<0.3 \mathrm{~m}$ or $\left|H_{s s 1}-H_{s s 2}\right| / H_{s s 2}<30 \%$ ) could be regarded as consistency between SAR Level-2 and WW3 from the perspective of partitioning, and thereby remained.

Considering the above quality-controls, three swell height match-ups of Sentinel-1 WV Level-2 data collocated against reference are used in this study, as listed in Table 1.

Table 1. Three swell height match-up datasets of Sentinel-1 WV L2 data collocated against reference.

\begin{tabular}{ccccc}
\hline Name Of Match-Up & Reference Data & Period & $\begin{array}{c}\text { QC Filtering Applied to } \\
\text { Sentinel-1 L2 Data }\end{array}$ & Data Points Number \\
\hline S1L2Buoy & Buoy & $2016.7-2020.6$ & L3QC + WW3QC & 3093 \\
S1L2WW3-1 & WW3 & $2016.7-2019.6$ & L3QC + WW3QC & WV1:468520 \\
S1L2WW3-2 & WW3 & $2019.7-2020.6$ & L2QC + L3QC + WW3QC & WV1:54583 \\
& & & & WV2:39328 \\
\hline
\end{tabular}

\subsection{Validation Results of Level-2}

The assessment of Sentinel-1 WV Level-2 swell heights (Hss) was carried out through the intercomparison of SAR products and those from the reference data. The statistics of bias, Root Mean Square Error (RMSE), and correlation coefficient (COR) used are expressed by

$$
\begin{gathered}
\text { bias }=\frac{1}{N} \sum_{i=1}^{N}\left(y_{i}-x_{i}\right), \\
\operatorname{RMSE}=\sqrt{\frac{1}{N} \sum_{j=1}^{N}\left(y_{i}-x_{i}\right)^{2},} \\
\operatorname{COR}=\frac{\sum_{i=1}^{N}\left(x_{i}-\left\langle x_{i}\right\rangle\right)\left(y_{i}-\left\langle y_{i}\right\rangle\right)}{\sqrt{\sum_{i=1}^{N}\left(x_{i}-\left\langle x_{i}\right\rangle\right)^{2} \sum_{i=1}^{N}\left(y_{i}-\left\langle y_{i}\right\rangle\right)^{2}}},
\end{gathered}
$$

where $x_{i}$ and $y_{i}$ represent the swell wave heights from reference data and Sentinel-1 SAR, and $N$ is the sample size. 
Based on the co-located dataset S1L2Buoy, validation of swell significant wave height against buoys shows a bias of $0.18 \mathrm{~m}$ and RMSE of $0.5 \mathrm{~m}$ for Sentinel-1A/B WV Level-2 products, with a scatter plot represented in Figure 10. The assessments against WW3 hindcast are presented as scatter plots in Figures 11 and 12, based on S1L2WW3-1 and S1L2WW3-2, respectively. All intercomparisons reveal the systematic overestimation of the Sentinel-1 Level-2 swell heights with respect to the reference. Furthermore, the black solid lines presenting median values in Figures 11 and 12 indicate that the biases tend to be sea-state dependent.

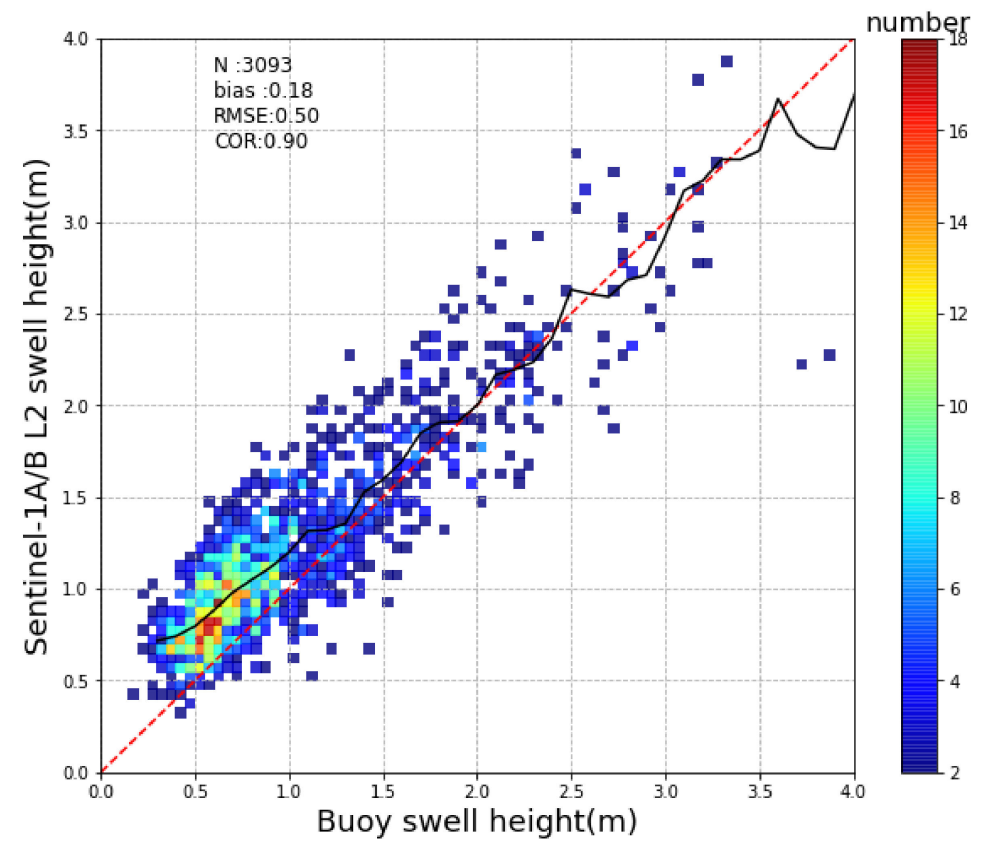

Figure 10. Intercomparisons of the partitioned swell heights for S-1A/B versus buoy, from match-ups of S1L2Buoy, as defined in Table 1. Colors denote the number of data points within $0.1 \mathrm{~m} \times 0.1 \mathrm{~m}$ bins. The superposed solid lines provide the median $y$-axis value for each $x$-axis bin.

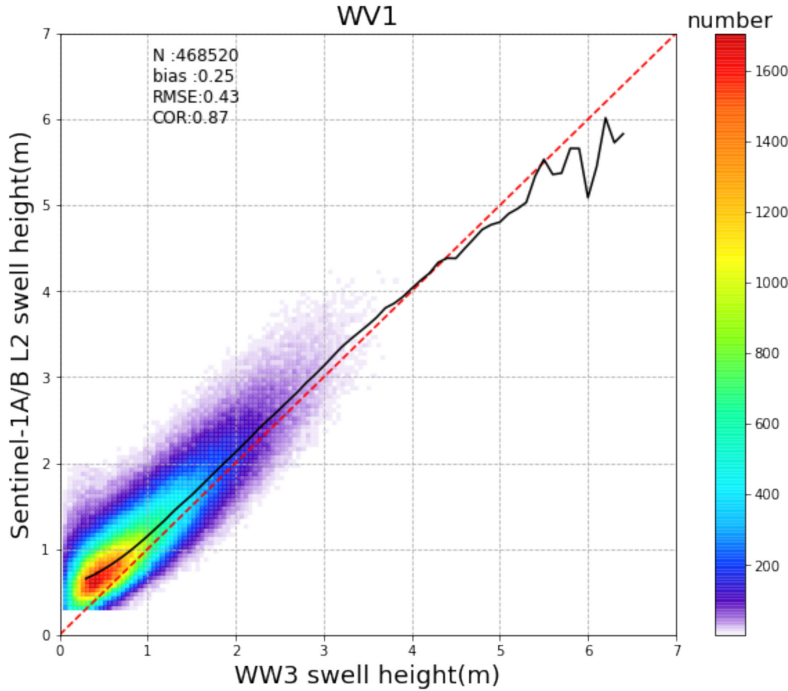

(a)

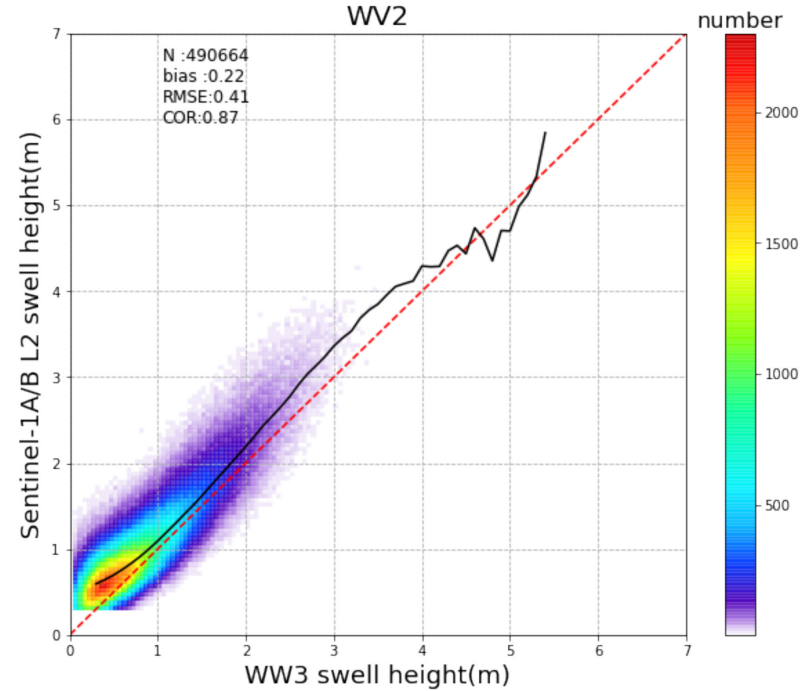

(b)

Figure 11. Intercomparisons of the partitioned swell heights for S-1A/B versus WW3 hindcasts, from match-ups of S1L2WW3-1, as defined in Table 1. (a) The results with the S-1A/B data in WV1 (incidence angle of $23.5^{\circ}$ ) and (b) WV2 (incidence angle of $36.5^{\circ}$ ). 


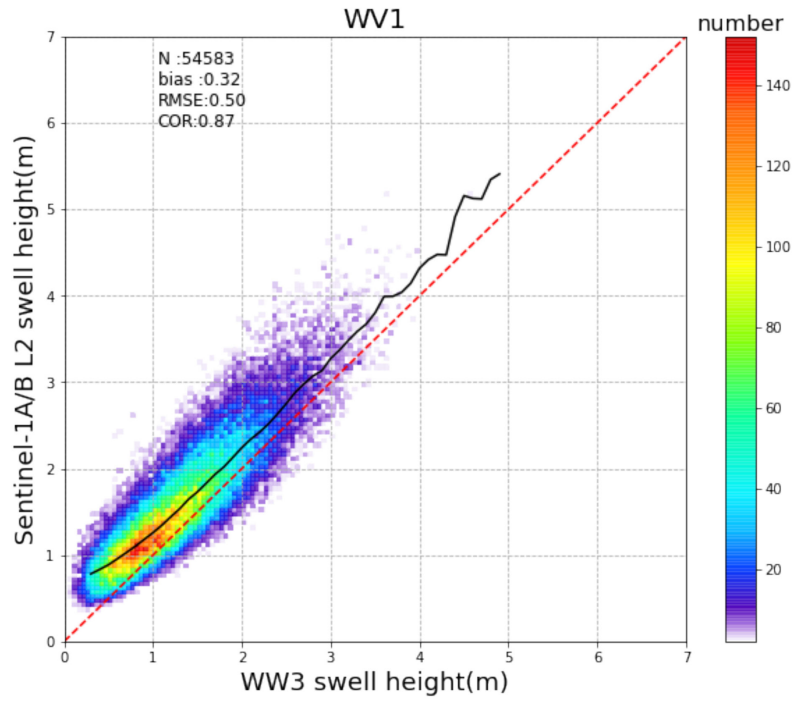

(a)

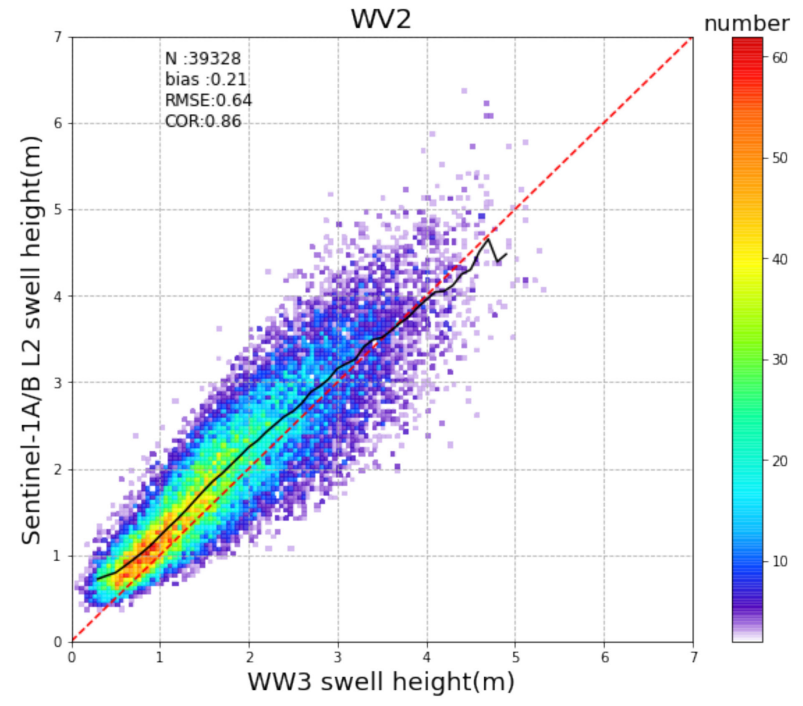

(b)

Figure 12. As in Figure 11, but for match-ups of WW3-2. (a) The results with the S-1A/B data in WV1 and (b) WV2.

We also investigate the influence of the incidence angle of $23.5^{\circ}$ (WV1) and $36.5^{\circ}$ (WV2), on the validation results. The results are shown in the left and right columns in Figures 11 and 12, presenting different bias tendencies against the reference (WW3).

\section{Correction of Sentinel-1 Level-2 Hss}

In order to correct the systematic errors of Sentinel-1 Level-2 swell heights, we proposed a significant swell height correction given by

$$
H_{s S L 2_{c o r r}}=\mathrm{a} \cdot H_{S S L 2}+\mathrm{b},
$$

where $H_{S S L 2_{\text {corr }}}$ and $H_{S S L 2}$ denote the SAR swell wave heights corrected in this paper and official released by ESA, respectively, and $a, b$ are coefficients depending on SAR-derived wind speed $U_{10}$ contained in Level-2 products (determined by a SAR-observed normalized radar cross section using geophysical model function of CMOD5.n [42]):

$$
\begin{aligned}
& \mathrm{a}=a_{1} \cdot U_{10}+a_{2} \\
& \mathrm{~b}=b_{1} \cdot U_{10}+b_{2} .
\end{aligned}
$$

Since the dataset of S1L2WW3-2 has enough samples (compared to the smaller S1L2Buoy match-ups) and is more reliable than S1L2WW3-1 (L2QC were not applied), we used S1L2WW3-2 to tune the coefficients when employing the Ordinary Least Squares (OLS) regression. The separate fittings were carried out for the two incidence angles mode of WV1 and WV2. The coefficients of the empirical correction are presented in Table 2.

Table 2. Correction coefficients.

\begin{tabular}{ccccc}
\hline Incidence Angle & $\boldsymbol{a}_{1}$ & $\boldsymbol{a}_{2}$ & $\boldsymbol{b}_{1}$ & $\boldsymbol{b}_{2}$ \\
\hline $\mathrm{WV} 1\left(23.5^{\circ}\right)$ & 0.0009 & 1.0129 & -0.0049 & 1.1150 \\
$\mathrm{WV} 2\left(36.5^{\circ}\right)$ & 0.0089 & -0.3569 & 0.0082 & -0.4173 \\
\hline
\end{tabular}

The performance of the proposed correction was then evaluated using two independent datasets of S1L2WW3-1 and S1L2Buoy. Figure 13 shows the verification results based on independent WW3 hindcasts (S1L2WW3-1). Compared to Figure 11, the corrected SAR 
swell heights present negligible bias with 17\% reduced RMSE (0.36 m corrected versus 0.43 m original for WV1 case).

Here we further introduce the metric called unbiased RMSE with the definition of (e.g., [43]):

$$
\text { ubRMSE }=\sqrt{\frac{1}{N} \sum_{j=1}^{N}\left[\left(y_{i}-\left\langle y_{i}\right\rangle\right)-\left(x_{i}-\left\langle x_{i}\right\rangle\right)\right]^{2}} .
$$

In terms of ubRMSE, negligible discrepancy between original (0.3642 $\mathrm{m}$ for WV1) and corrected data $(0.3598 \mathrm{~m}$ for WV1) could be found. This indicates that the reduced bias and the linear correction coefficients leads to the RMSE reduction.

Similarly, as shown in Figure 14, the assessment based on S1L2Buoy match-ups also demonstrates the elimination of the systematic bias with the agreement between the corrected SAR swell height and buoy in situ reference.

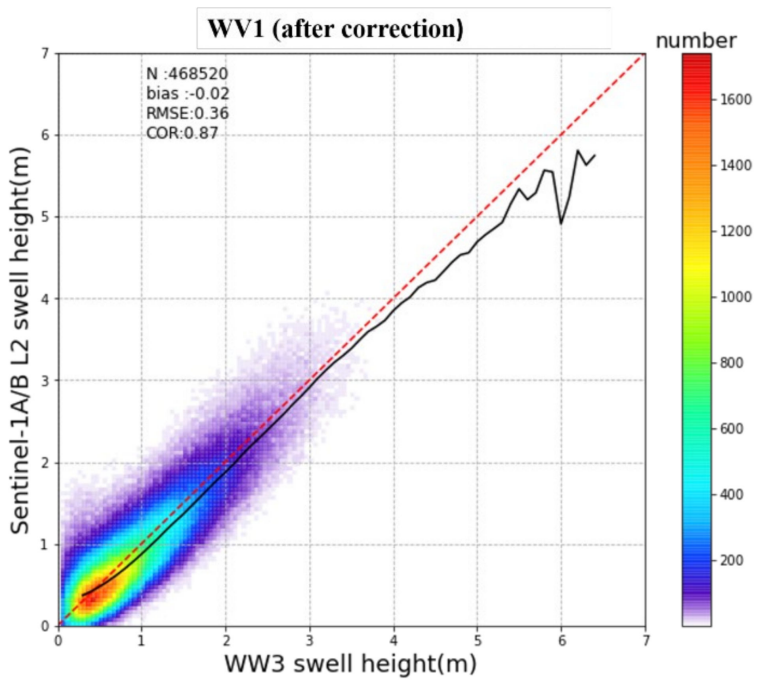

(a)

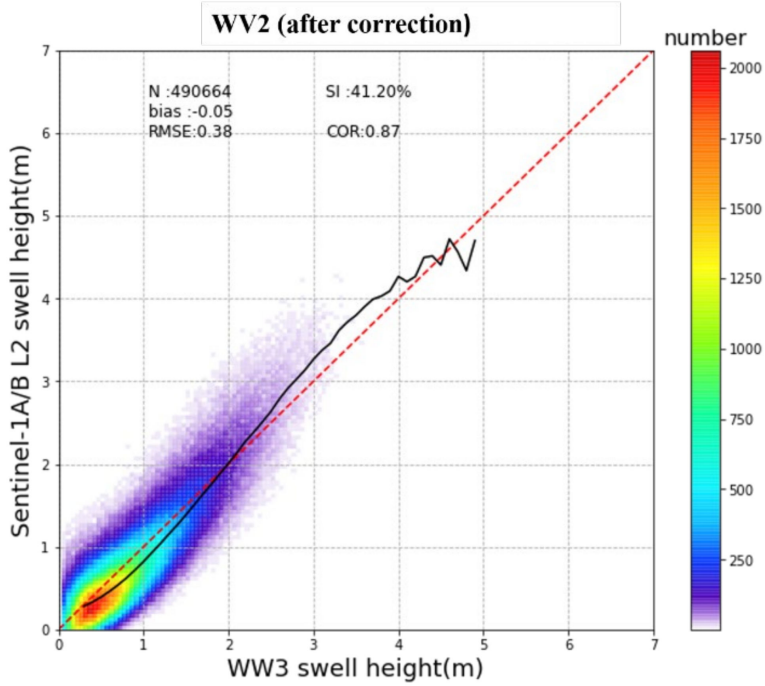

(b)

Figure 13. As in Figure 11, but after correction. (a) The results with the S-1A/B data in WV1 and (b) WV2.

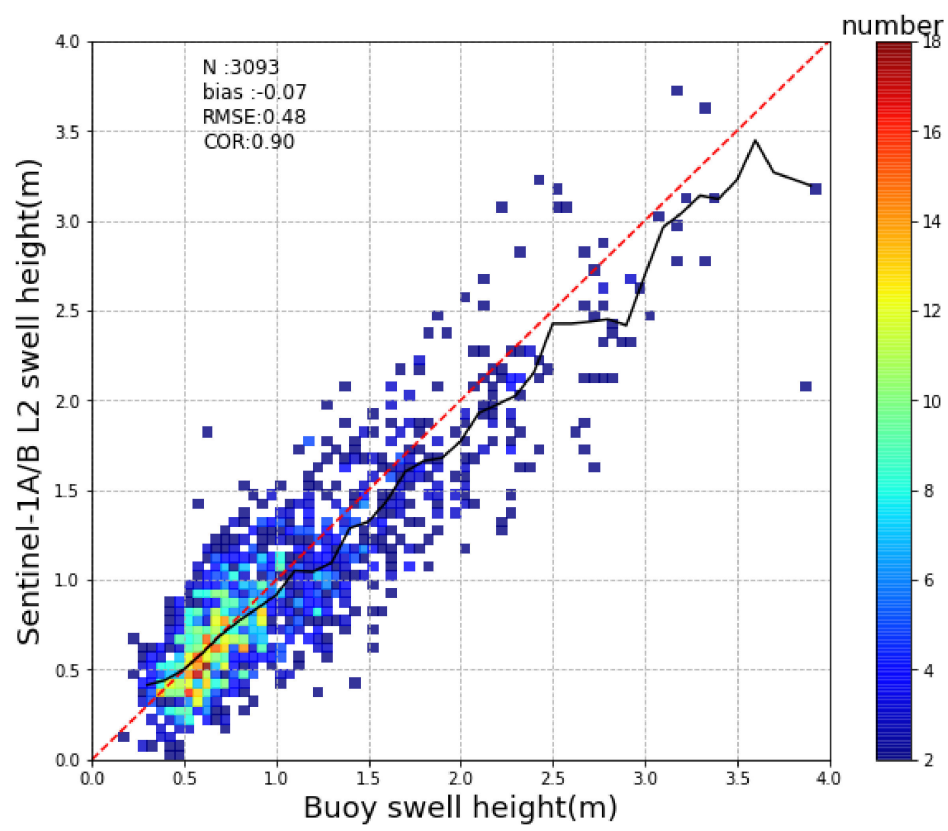

Figure 14. As in Figure 10, but after correction. 


\section{Assessment of Sentinel-1 Level-3 Hss Products}

Here, we apply the concept of the "virtual wave observer" proposed by Collard et al. [14] to compare the Level-3 swell products against in situ measurements. For each in-situ buoy, a virtual wave observer is defined by the vicinity centered on the buoy location with a radius of $100 \mathrm{~km}$. All swell systems from the Sentinel-1 Level-3 "fireworks" product intercepting this area are then considered as observed data by a "virtual buoy" obtained with the satellite. Then, each propagated swell parameter measurement obtained at the virtual buoy for a given time can be directly compared to the swell partition observed from the real buoy station closest in time, resulting in a quality assessment of the Level-3 "fireworks" swell product.

Figure 15a shows the comparison results of Sentinel-1 Level-3 swell heights and buoy measurements. Unsurprisingly, the positive bias (approximately $0.2 \mathrm{~m}$ ) is still found in Level-3 wave height products, which is mainly inherited from systematic overestimation in Level-2 data. In the processing of "fireworks", the Level-3 swell heights $H_{s s L 3}$ were estimated from Level-2 observations $\left(H_{s s L 2}\right)$, according to the swell energy evolution model [14,17]:

$$
H_{s s L 3}(\alpha)=\sqrt{\alpha_{0} \sin \alpha_{0} /(\alpha \sin \alpha)} e^{-\mu\left(\alpha-\alpha_{0}\right) / 2} H_{s s L 2}\left(\alpha_{0}\right),
$$

where $\alpha_{0}$ and $\alpha$ represent the angular great circle distance from the storm source to SAR observations (Level-2) and any propagated locations (Level-3), and $\mu$ is a constant of swell dissipation rate. Note that this is valid only if the propagated location is in the far field (more than $4000 \mathrm{~km}$ from the origin inferred from "fireworks" analysis).

From Equation (11), the Level-3 swell heights could be corrected using the Level-2 corrections $H_{s s L 2_{\text {corr }}}$ (see Equation (8)):

$$
H_{S S L 3 \_c o r r}=H_{S S L 3} * H_{S S L 2} \text { corr } / H_{S S L 2} \text {. }
$$

As shown in Figure 15b, the bias of the Sentinel-1 Level-3 swell height is efficiently eliminated after applying the correction against the buoy observations.

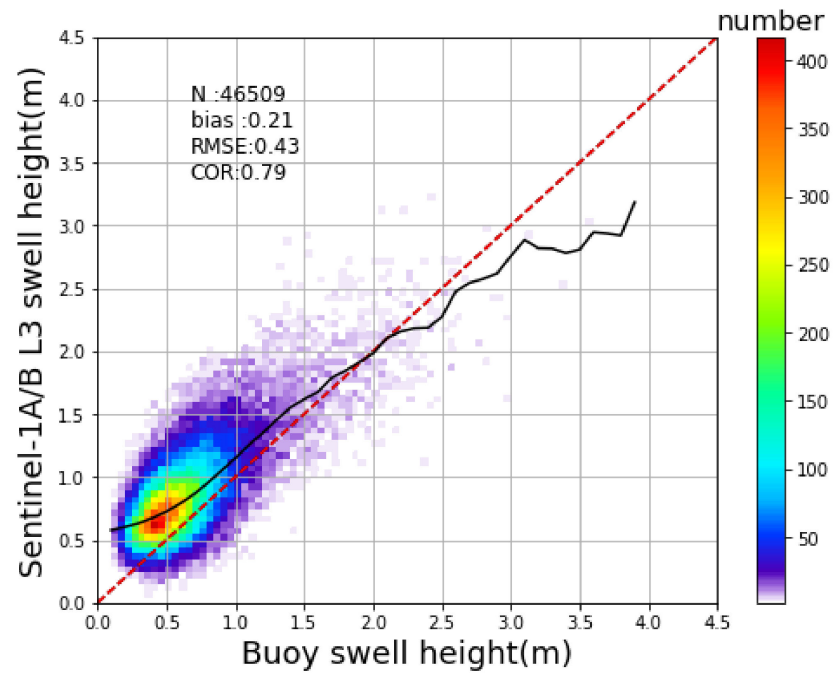

(a)

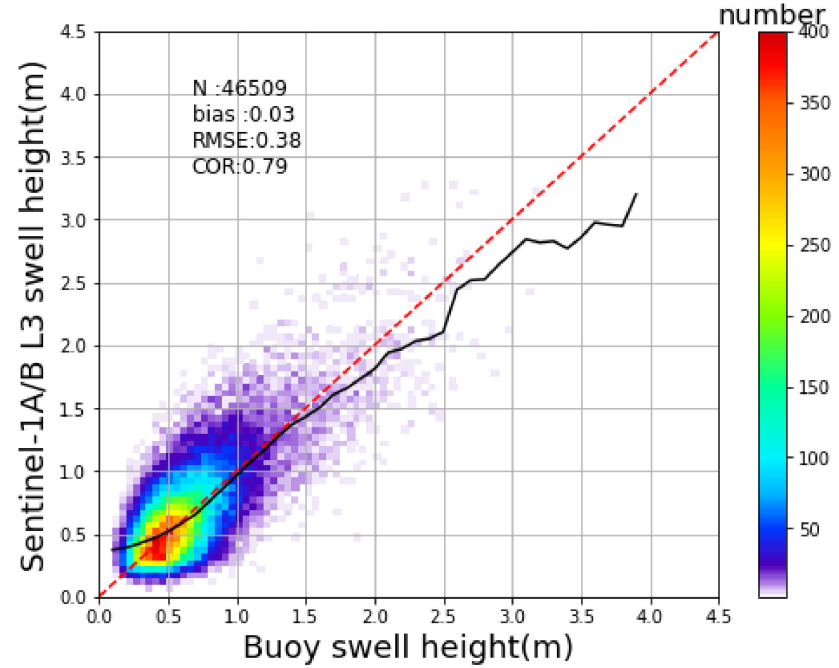

(b)

Figure 15. Intercomparisons of the partitioned swell heights for S-1A/B Level-3 versus buoys. (a) Original Level-3 SAR products from CMEMS, and (b) corrected using Equation (12).

\section{Virtual Observer from Level-3 Swells: Case Studies}

\subsection{Swell Event Generated by Extra-Tropical Storm on 28 July 2016}

As shown in Figure 3, the swell event originated by an extra-tropical storm on 28 July 2016 was successfully reconstructed by the Sentinel-1 Level-3 swells from space with quite 
a dense coverage of measurements across the Pacific Ocean. At Stratus buoy station, the evolution of the integral swell parameters for this event from the 2nd to 7th of August is presented in Figure 16 for the Level-3 swell (blue and red dots for observations of WV1 and WV2), buoy in situ (black dots), and WW3 modelling (yellow dots). As illustrated, regarding the peak wavelength from Level-3 "fireworks" swells, the arrival of the longest wavelength before the smallest is in line with the theory of linear swell propagation and compares very well with the real buoy records or modelling (see Figure 16 middle). The difference for the peak directions of the incident swells is always lower than $25^{\circ}$ as shown in Figure 16 bottom. The increasing trend of the significant wave height at first followed by a decrease after a maximum of intensity ( $2.0 \mathrm{~m}$ approximately around August $2 \mathrm{nd})$ is also in line with theory and compares very well with the reference data both from in situ and modelling from Figure 16 top.

Note that after the 6 August 2016, a new swell system being originated from another storm starts to arrive at the Stratus buoy station. Again, the longest wavelength arrives first, the significant wave height is small at first but increases with time. The incident wave directions are different than in our case study, indicating that the location of the storm is not the same.

NDBC Buoy 32012 (Swell from extra-tropical storm)
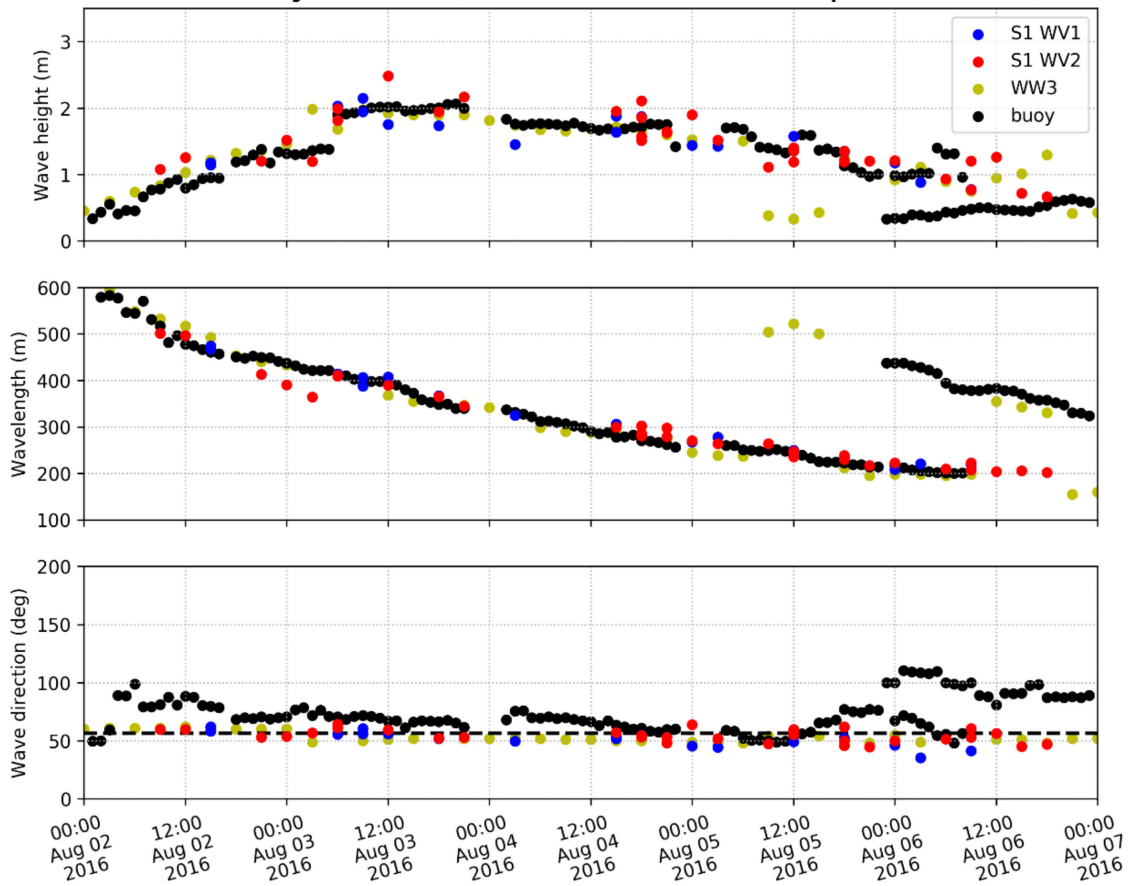

Figure 16. Comparison of significant wave height (top), peak wavelength (middle), and peak direction (bottom) from Level-3 CMEMS "fireworks" SAR products (red and blue dots representing Sentinel-1 SAR data in WV1 and WV2, respectively), buoy measurements (black dots) and WW3 model (yellow dots) at the Stratus buoy station \#32012 $\left(19.63^{\circ} \mathrm{S} / 84.95^{\circ} \mathrm{W}\right)$ during the swell event generated by an extra-tropical storm on 28 July 2016.

\subsection{Swell Event Generated by Typhoon Lionrock on 29 August 2016}

From the CMEMS Level-3 products, the swells generated by the intense Typhoon Lionrock travelled across the Pacific Ocean from southeast of Japan, and eventually reached the coast off south America (Stratus buoy \#32012), as illustrated in Figure 4. However, our analysis of the integral swell parameters evolution from September 9th to 17th 2016 at the Stratus station, presented in Figure 17 top, reveals no corresponding (propagating towards southeast $\left(100^{\circ}-125^{\circ}\right)$ originated from Lionrock-generated swell records from the real buoy, while both WW3 modelling and SAR derived Level-3 product present a very weak wave height signal. Despite this weak signature in the wave height, WW3 and Level-3 signals 
are very consistent in terms of peak wavelength and direction, shown in Figure 17 middle and bottom, respectively. Specifically, from the two-dimensional ocean wave spectrum, shown in Figure 7, observed from buoy \#32012 on 12:00:00 UTC 11 September, one could not discover the swell partition signal propagating towards southeast from the Typhoon Lionrock, although three swells propagating towards northeast, and north can be seen.

In contrast, in the location closer to the swell origin, for instance the buoy \#46059 $\left(38.05^{\circ} \mathrm{N} / 129.90^{\circ} \mathrm{E}\right.$ ) off California (about $7500 \mathrm{~km}$ away from the storm, half distance in comparison to NDBC buoy \#32012), swell parameters generated from this Typhoon event show consistency from the triple comparison from September 4 th to 9 th, as presented in Figure 18.

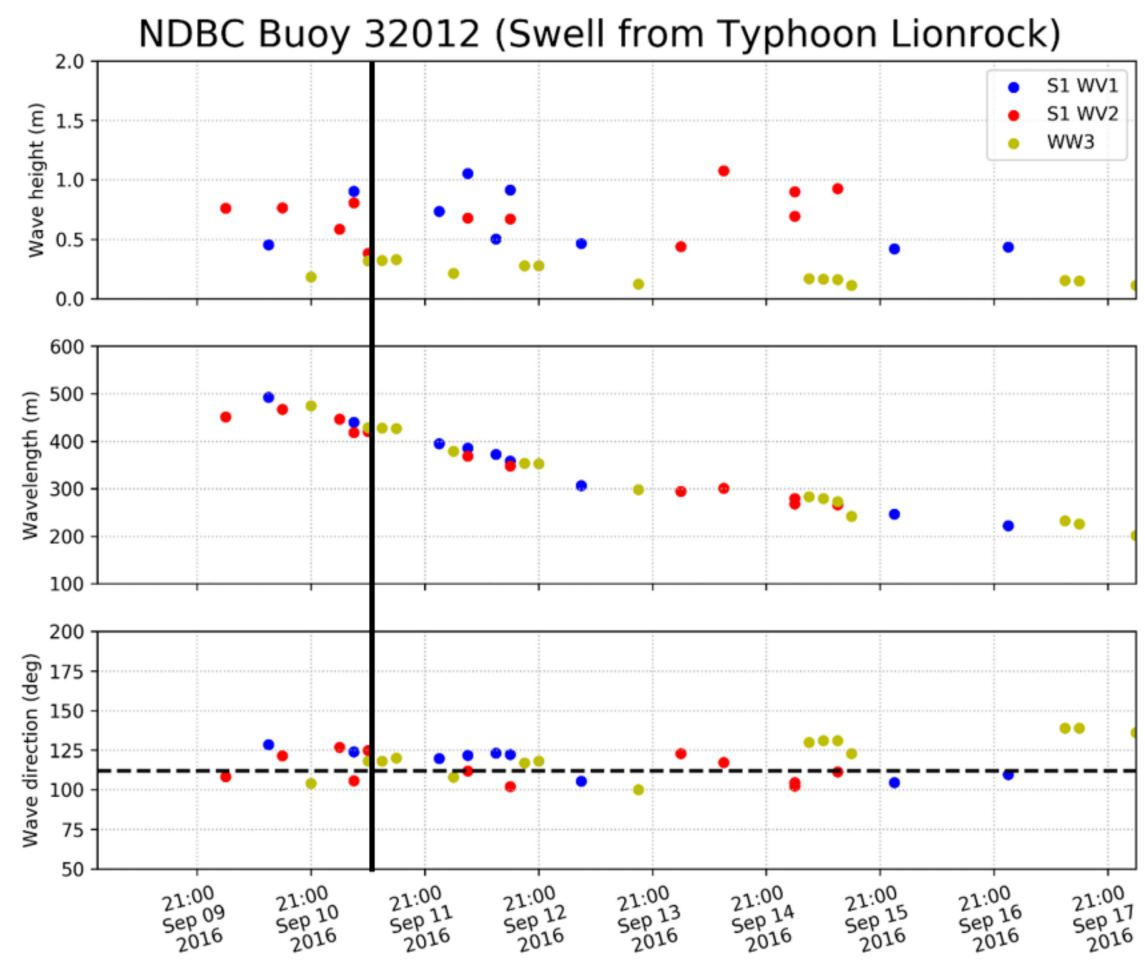

Figure 17. As in Figure 16, but for the case of a swell event originated from Typhoon Lionrock on 29 August 2016. The vertical black line corresponds to 12:00:00 UTC 11 September 2016 (the time of buoy observation presented in Figure 7).

Possible explanations for the discrepancy observed at Stratus station location could be the uncertainty in the swell dissipation law applied to SAR observations owing to the too long propagation distance. The method used to build the Level-3 product assumes propagation in the deep ocean without any swell-current interactions. For long propagation potentially crossing the ocean surface current, wave-current interactions may impact the swell energy [44]. In addition, in this particular case of fast-moving tropical cyclone, errors in the location in time and/or space may also lead to uncertainty in the production of Level-3 "fireworks" swell data. This will also impact more long-distant propagation.

Besides, the energy of swell would be very small after propagation across almost the entire Pacific as provided from space and modelling, and these weak signals (if indeed detected by Stratus buoy) are likely to be merged and smeared in the buoy angular distribution, therefore leading to difficulty in swell extraction by partitioning. 

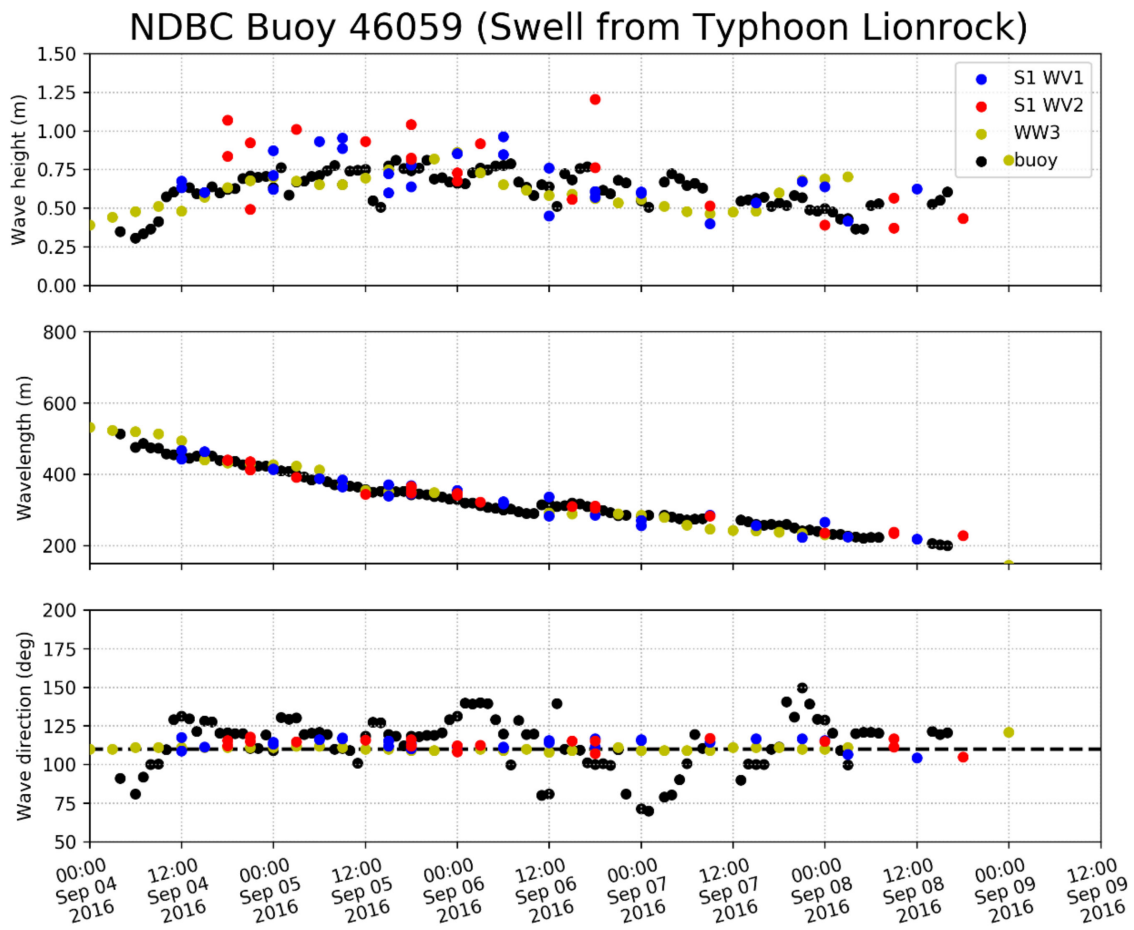

Figure 18. As in Figure 16, but for the case of a swell event originated from Typhoon Lionrock on 29 August at the buoy $\# 46059$ (38.05 $\left.\mathrm{N} / 129.90^{\circ} \mathrm{E}\right)$.

\section{Conclusions}

In this study, the accuracy of the SAR-derived partitioned swell wave height products from the Sentinel-1A/B satellites operating in wave mode has been assessed over the period from June 2016 and June 2020 by comparison against moored buoys observations (deployed in eastern Pacific and the western Atlantic) and WW3 modeling. A brief summary can be given as follows:

(1) Regarding the Level-2 products of Sentinel-1A/B swell heights, the quality assessments through SAR-WW3 and SAR-buoy intercomparisons reveal a systematic overestimation of approximately $0.2 \mathrm{~m}$ in terms of the partitioned swell heights;

(2) An empirical correction model for Sentinel-1 Level-2 swell heights has been proposed based on the reliable SAR-WW3 match-ups after quality-controls, with respect to the two incidence angles mode of WV1 and WV2;

(3) The verification of the correction was carried out by comparing the corrected Level-2 swell heights against independent WW3 hindcasts and buoy observations. In addition, by applying the proposed Level-2 corrections, the errors in CMEMS Level-3 swell heights are efficiently reduced;

(4) The consistency between CMEMS Level-3 swells and buoy in situ has been examined and discussed by case studies. Despite the overall good quality, the inter-comparison also indicates uncertainties in the Level-3 product when propagating too long a distance from the Sentinel-1 Level-2 observations.

In the validation practice, filtering out suspicious wave spectra derived from inhomogeneous SAR images contaminated by non-wave phenomena could be further taken into consideration to improve the quality assessment. Recently, a convolutional neural network has been employed to classify the Sentinel- 1 wave mode imagery into different categories according to the SAR roughness $[45,46]$. In the future, we plan to exploit these labeled SAR images to refine our validation and correction results. 
Author Contributions: Conceptualization, H.W.; investigation, H.W., A.M., R.H., J.Y. and A.G.; supervision, B.C.; writing-original draft, H.W. All authors have read and agreed to the published version of the manuscript.

Funding: This work was supported by the National Key Research and Development Program of China under grant 2021YFC2803304, and the European Space Agency and Chinese Ministry of Science and Technology Dragon 5 Cooperation Programme under grant 58009.

Institutional Review Board Statement: Not applicable.

Informed Consent Statement: Not applicable.

Data Availability Statement: Publicly available datasets were analyzed in this study. These include Sentinel-1A/B Level-2 wave mode data from https: / / scihub.copernicus.eu/dhus/\#/home, accessed on 29 December 2021 (see user guide at https://scihub.copernicus.eu/userguide/, accessed on 29 December 2021), IOWAGA WaveWatch-III model hindcast from ftp:/ ftp.ifremer.fr/ifremer/ ww3/HINDCAST/GLOBAL (accessed on 29 December 2021), National Data Buoy Center (NDBC) buoy measurements from https:/ / www.ndbc.noaa.gov/data/historical/swr1 ( $r_{1}$, accessed on 29 December 2021); https: / / www.ndbc.noaa.gov / data/historical/swr2 ( $r_{2}$, accessed on 29 December 2021); https: / / www.ndbc.noaa.gov/data/historical/swdir/ $\left(\alpha_{1}\right.$, accessed on 29 December 2021); https://www.ndbc.noaa.gov/data/historical/swdir2/ ( $\alpha_{2}$, accessed on 29 December 2021); and Coastal Data Information Program (CDIP) buoy in situ via http:/ / cdip.ucsd.edu/, accessed on 29 December 2021 (see data access instruction available at http:/ / cdip.ucsd.edu/data_access/ndar.cdip? help, accessed on 29 December 2021).

Acknowledgments: The authors are grateful to the two anonymous reviewers for their constructive comments and suggestions that helped improve this paper.

Conflicts of Interest: The authors declare no conflict of interest.

\section{References}

1. Semedo, A.; Sušelj, K.; Rutgersson, A.; Sterl, A. A Global View on the Wind Sea and Swell Climate and Variability from ERA-40. J. Clim. 2011, 24, 1461-1479. [CrossRef]

2. Li, X.-M. A new insight from space into swell propagation and crossing in the global oceans. Geophys. Res. Lett. 2016, 43, 5202-5209. [CrossRef]

3. Chen, G.; Chapron, B.; Ezraty, R.; Vandemark, D. A global view of swell and wind sea climate in the ocean by satellite altimeter and scatterometer. J. Atmos. Ocean. Technol. 2002, 19, 1849-1859. [CrossRef]

4. Dobrynin, M.; Murawski, J.; Baehr, J.; Ilyina, T. Detection and Attribution of Climate Change Signal in Ocean Wind Waves. J. Clim. 2015, 28, 1578-1591. [CrossRef]

5. Lemos, G.; Semedo, A.; Hemer, M.; Menendez, M.; Miranda, P.M.A. Remote climate change propagation across the oceans-The directional swell signature. Environ. Res. Lett. 2021, 16, 64080. [CrossRef]

6. Hasselmann, K.; Chapron, B.; Aouf, L.; Ardhuin, F.; Collard, F.; Engen, G.; Hasselmann, S.; Heimbach, P.; Janssen, P.; Johnsen, H.; et al. The ERS SAR wave mode: A breakthrough in global ocean wave observations. In ERS Missions: 20 Years of Observing Earth, 1st ed.; Fletcher, K., Ed.; European Space Agency: Noordwijk, The Netherlands, 2013; pp. 165-198.

7. Miranda, N.; Rosich, B.; Meadows, P.J.; Haria, K.; Small, D.; Schubert, A.; Lavalle, M.; Collard, F.; Johnsen, H.; Guarnieri, A.M. The EnviSAT ASAR Mission: A Look Back at 10 Years of Operation; European Space Agency Special Publication: Paris, France, 2013.

8. Wang, H.; Wang, J.; Yang, J.S.; Ren, L.; Zhu, J.H.; Yuan, X.Z.; Xie, C.H. Empirical algorithm for significant wave height retrieval from wave mode data provided by the Chinese satellite Gaofen-3. Remote Sens. 2018, 10, 363. [CrossRef]

9. Wang, H.; Li, H.; Lin, M.; Zhu, J.; Wang, J.; Li, W.; Cui, L. Calibration of the Copolarized Backscattering Measurements from Gaofen-3 Synthetic Aperture Radar Wave Mode Imagery. IEEE J. Selected Top. Appl. Earth Observ. Remote Sens. 2019, 12, 1748-1762. [CrossRef]

10. Portilla-Yandun, J.; Valladares, C.; Violante-Carvalho, N. A hybrid physical-statistical algorithm for SAR wave spectra quality assessment. IEEE J. Sel. Top. Appl. Earth Obs. Remote Sens. 2019, 12, 3943-3948. [CrossRef]

11. Jiang, H.; Mouche, A.; Wang, H.; Babanin, A.; Chapron, B.; Chen, G. Limitation of SAR quasi-linear inversion data on swell climate: An example of global crossing swells. Remote Sens. 2017, 9, 107. [CrossRef]

12. Snodgrass, F.E.; Groves, G.W.; Hasselmann, K.F.; Miller, G.R.; Munk, W.H.; Powers, W.H. Propagation of Ocean Swell across the Pacific. Philos. Trans. R. Soc. A Math. Phys. Eng. Sci. 1966, 259, 431-497.

13. Munk, W.H.; Miller, G.R.; Snodgrass, F.E.; Barber, N.F. Directional recording of swell from distant storms. Philos. Trans. R. Soc. A Math. Phys. Eng. Sci. 1963, 255, 505-584. [CrossRef] [PubMed]

14. Collard, F.; Ardhuin, F.; Chapron, B. Monitoring and analysis of ocean swell fields from space: New methods for routine observations. J. Geophys. Res. 2009, 114, C07023. [CrossRef] 
15. Husson, R.; Ardhuin, F.; Collard, F.; Chapron, B.; Balanche, A. Revealing forerunners on Envisat wave mode ASAR using the Global Seismic Network. Geophys. Res. Lett. 2012, 39, L15609. [CrossRef]

16. Wang, H.; Mouche, A.; Husson, R.; Chapron, B. Indian Ocean Crossing Swells: New Insights from "fireworks" perspective using Envisat Advanced Synthetic Aperture Radar. Remote Sens. 2021, 13, 670. [CrossRef]

17. Ardhuin, F.; Chapron, B.; Collard, F. Observation of swell dissipation across oceans. Geophys. Res. Lett. 2009,36, L06607. [CrossRef]

18. Stopa, J.E.; Ardhuin, F.; Husson, R.; Jiang, H.; Chapron, B.; Collard, F. Swell dissipation from 10 years of Envisat advanced synthetic aperture radar in wave mode. Geophys. Res. Lett. 2016, 43, 3423-3430. [CrossRef]

19. Delpey, M.T.; Ardhuin, F.; Collard, F.; Chapron, B. Space-time structure of long ocean swell fields. J. Geophys. Res. 2010, 115, C12037. [CrossRef]

20. Le Traon, P.Y.; Reppucci, A.; Alvarez Fanjul, E.; Aouf, L.; Behrens, A.; Belmonte, M.; Bentamy, A.; Bertino, L.; Brando, V.E.; Kreiner M.B.; et al. From Observation to Information and Users: The Copernicus Marine Service Perspective. Front. Mar. Sci. 2019, 6, 234. [CrossRef]

21. Alday, M.; Accensi, M.; Ardhuin, F.; Dodet, G. A global wave parameter database for geophysical applications. Part 3: Improved forcing and spectral resolution. Ocean. Model. 2021, 166, 101848. [CrossRef]

22. Sun, M.; Yang, Y.; Yin, X.; Du, J. Data assimilation of ocean surface waves using Sentinel-1 SAR during typhoon Malakas. Int. J. Appl. Earth Obs. Geoinf. 2018, 70, 35-42. [CrossRef]

23. Shao, W.; Zhang, Z.; Li, X.F.; Li, H. Ocean wave parameters retrieval from Sentinel-1 SAR imagery. Remote Sens. 2016,8 , 707. [CrossRef]

24. Mouche, A.; Wang, H.; Husson, R.; Guitton, G.; Chapron, B.; Li, H. 2D ocean waves spectra from space: A challenge for validation and synergetic use. SPIE Asia Pac. Remote Sens. 2016, 9878, 98780L.

25. Stopa, J.E.; Mouche, A. Significant wave heights from Sentinel-1 SAR: Validation and applications. J. Geophys. Res. Ocean. 2017, 122, 1827-1848. [CrossRef]

26. Khan, S.S.; Echevarria, E.R.; Hemer, M.A. Ocean Swell Comparisons Between Sentinel-1 and WAVEWATCH III Around Australia. J. Geophys. Res. 2021, 126, e2020JC016265. [CrossRef]

27. Wang, H.; Mouche, A.; Husson, R.; Chapron, B. Dynamic validation of ocean swell derived from Sentinel-1 wave mode against buoys. In Proceedings of the 2018 IEEE International Geoscience and Remote Sensing Symposium, Valencia, Spain, 22-27 July 2018; pp. 3223-3226.

28. Engen, G.; Johnsen, H. SAR-ocean wave inversion using image cross spectra. IEEE Trans. Geosci. Remote Sens. 1995, 33, 1047-1056. [CrossRef]

29. Chapron, B.; Johnsen, H.; Garello, R. Wave and wind retrieval from SAR images of the ocean. Ann. Telecommun. 2001, 56, 682-699. [CrossRef]

30. Johnsen, H.; Collard, F. Sentinel-1 Ocean Swell Wave Spectra (OSW) Algorithm Definition. Tech. Rep. 13, NORUT. 2009. Available online: https:/ / sentinel.esa.int/documents/247904/0/S-1_L2_OSW_Detailed_Algorithm_Definition.pdf/46372081-4a3c-44 1b-91c9-eee5aa475bbc (accessed on 3 December 2021).

31. Husson, R. Development and Validation of a Global Observation-Based Swell Model Using Wave Mode Operating Synthetic Aperture Radar. Ph.D. Thesis, Université de Bretagne Occidentale, Brest, France, 2012.

32. Desbiolles, F.; Bentamy, A.; Blanke, B.; Roy, C.; Mestas-Nuñez, A.M.; Grodsky, S.A.; Herbette, S.; Cambon, G.; Maes, C. Two decades [1992-2012] of surface wind analyses based on satellite scatterometer observations. J. Mar. Syst. 2017, 168, 38-56. [CrossRef]

33. Mouche, A.; Chapron, B.; Zhang, B.; Husson, R. Combined Co- and Cross-Polarized SAR Measurements under Extreme Wind Conditions. IEEE Trans. Geosci. Remote Sens. 2017, 55, 6746-6755. [CrossRef]

34. Wang, H.T.; Freise, C.B. Error analysis of the directional wave spectra obtained by the NDBC 3-m pitch-roll discus buoy. IEEE J. Ocean. Eng. 1997, 22, 639-648. [CrossRef]

35. O'Reilly, W.; Olfe, C.B.; Thomas, J.; Seymour, R.; Guza, R. The California coastal wave monitoring and prediction system. Coast. Eng. 2016, 116, 118-132. [CrossRef]

36. Lygre, A.; Krogstad, H.E. Maximum entropy estimation of the directional distribution in ocean wave spectra. J. Phys. Oceanogr. 1986, 16, 2052-2060. [CrossRef]

37. Portilla, J.; Ocampo-Torres, F.J.; Monbaliu, J. Spectral partitioning and identification of wind sea and swell. J. Atmos. Ocean. Technol. 2009, 26, 107-122. [CrossRef]

38. Ardhuin, F.; Rogers, E.; Babanin, A.V.; Filipot, J.-F.; Magne, R.; Roland, A.; van der Westhuysen, A.; Queffeulou, P.; Lefevre, J.-M.; Aouf, L.; et al. Semiempirical Dissipation Source Functions for Ocean Waves. Part I: Definition, Calibration, and Validation. J. Phys. Oceanogr. 2010, 40, 1917-1941. [CrossRef]

39. Rascle, N.; Ardhuin, F. A global wave parameter database for geophysical applications. Part 2: Model validation with improved source term parameterization. Ocean Model. 2013, 70, 174-188. [CrossRef]

40. Mentaschi, L.; Besio, G.; Cassola, F.; Mazzino, A. Performance evaluation of Wavewatch III in the Mediterranean Sea. Ocean Model. 2015, 90, 82-94. [CrossRef] 
41. ESA. Sentinel-1 A\&B Annual Performance Report for 2020. ESA. 16 March 2021. Available online: https://sentinel.esa.int/ documents/247904/4607145/Sentinel-1-Annual-Performance-Report-2020.pdf/1eac12a7-26ca-002c-b3ff-78f6a1d77653 (accessed on 3 December 2021).

42. Verhoef, A.; Portabella, M.; Stoffelen, A.; Hersbach, H. CMOD5.n-The CMOD5 GMF for Neutral Winds. Tech. Note SAF/OSI/CDOP/KNMI/TEC/TN/165. 2008. Available online: https://digital.csic.es/bitstream/10261/156198/1/Verhoef_ et_al_2008.pdf (accessed on 13 December 2021).

43. Entekhabi, D.; Reichle, R.H.; Koster, R.D.; Crow, W.T. Performance Metrics for Soil Moisture Retrievals and Application Requirements. J. Hydrometeorol. 2010, 11, 832-840. [CrossRef]

44. Gallet, B.; Young, W.R. Refraction of swell by surface currents. J. Mar. Res. 2014, 72, 105-126. [CrossRef]

45. Wang, C.; Mouche, A.; Tandeo, P.; Stopa, J.E.; Longépé, N.; Erhard, G.; Foster, R.C.; Vandemark, D.; Chapron, B. A labelled ocean SAR imagery dataset of ten geophysical phenomena from Sentinel-1 wave mode. Geosci. Data J. 2019, 6, 105-115. [CrossRef]

46. Wang, C.; Tandeo, P.; Mouche, A.; Stopa, J.E.; Gressani, V.; Longepe, N.; Vandemark, D.; Foster, R.C.; Chapron, B. Classification of the global Sentinel-1 SAR vignettes for ocean surface process studies. Remote Sens. Environ. 2019, 234, 111457. [CrossRef] 